ÉGYPTE

monde arabe

\section{Égypte/Monde arabe}

5-6| 2009

Pratiques du Patrimoine en Égypte et au Soudan

\title{
Réutilisation des monuments historiques à des fins didactiques, culturelles ou artistiques
}

Reusing historic buildings for educational, cultural or artistic purposes

\section{Aymé Lebon}

\section{(2) OpenEdition}

\section{Journals}

Édition électronique

URL : https://journals.openedition.org/ema/2903

DOI : 10.4000/ema.2903

ISSN : 2090-7273

Éditeur

CEDEJ - Centre d'études et de documentation économiques juridiques et sociales

Édition imprimée

Date de publication : 22 décembre 2009

Pagination : 253-292

ISBN : 2-905838-43-4

ISSN : 1110-5097

Référence électronique

Aymé Lebon, «Réutilisation des monuments historiques à des fins didactiques, culturelles ou artistiques », Égypte/Monde arabe [En ligne], 5-6 | 2009, mis en ligne le 31 décembre 2010, consulté le 07 juillet 2022. URL : http://journals.openedition.org/ema/2903; DOI : https://doi.org/10.4000/ema. 2903 


\title{
Aymé LeBon
}

\section{RÉSUMÉ / ABSTRACT}

\author{
RÉAFFECTATION DES MONUMENTS HISTORIQUES À DES FINS \\ DIDACTIQUES, CULTURELLES OU ARTISTIQUES
}

Le tremblement de terre d'octobre 1992 a révélé l'état de précarité préoccupante de la quasi-totalité du patrimoine islamique cairote. L'appel à l'aide international de 1998 et les sommes importantes drainées ont généré un essor patrimonial sans précédent. Très vite, le Conseil Suprême des Antiquités (CSA) passe de la question du " comment conserver » à celle du « pourquoi » de la conservation. II ne faut jamais s'arrêter à la restauration des édifices historiques, puis les abandonner à leur sort. Seule une réutilisation judicieuse et respectueuse de leur caractère historique ou architectural pourrait garantir leur pérennité. La restauration n'étant pas une finalité en soi, à quoi donc peuvent bien servir tous ces monuments fraîchement réhabilités ? À travers de dix-sept monuments historiques du Caire, d'Alexandrie et de province, cet article s'attache à décrypter la politique de réaffectation ( $i$ 'âdat tawzîf) des monuments historiques à des fins didactiques, culturelles ou artistiques mise en place en Égypte entre 2000 et 2008.

\section{REUSING HISTORIC BUILDINGS FOR EDUCATIONAL, CULTURAL OR ARTISTIC PURPOSES}

The October 1992 earthquake revealed the precarious state of almost all of Cairene Islamic monuments. In 1998, the call for international assistance and the large amounts of money it generated have created the conditions of an unprecedented heritage boom. Very quickly, the Supreme Council of Antiquities (SCA) moved from the question of «how to preserve» to the Why of conservation. One should never stop at the restoration of historic buildings, and then abandon them to their fate. Only a judicious reuse could ensure their sustainability while maintaining their historic character and architecture. Since restoration is not an end in itself, what all these monuments freshly rehabilitated can be useful for? Studying the case of seventeen monuments of Cairo, Alexandria and Upper Egypt, this article attempts to decipher the politics of reallocation (i'âdat tawzîf) of buildings for educational, cultural or artistic purposes in Egypt between 2000 and 2008. 



\section{RÉAFFECTATION DES MONUMENTS HISTORIQUES À DES FINS DIDACTIQUES, CULTURELLES OU ARTISTIQUES}

« Restaurer un édifice, ce n'est pas l'entretenir, le réparer ou le refaire, c'est le rétablir dans un état complet qui peut n'avoir jamais existé à un moment donné !».

Eugène Viollet-le-Duc

L e tremblement de terre du 12 octobre 1992 et ses nombreuses répliques ont mis la quasi-totalité du patrimoine islamique dans un état de précarité préoccupante. Dès 1998, l'Égypte lance un projet de restauration du Caire historique assorti d'un appel à I'aide internationale. L'Unesco, I'Union européenne, I'United States Agency for International Development, I'Aga Khan Trust for Culture, le World Monuments Fund et d'autres organisations internationales se mobilisent aussitôt et font preuve d'une grande solidarité tant sur le plan technique que financier. Les dons affluent de toutes parts. Ils génèrent une impulsion sans précédent dans le sauvetage de plusieurs monuments, le financement de recherches et d'études de faisabilité, et la formation et l'entraînement des archéologues, des architectes et des restaurateurs. Une partie des fonds sera, inéluctablement, gaspillée et détournée par quelques fonctionnaires véreux. Le procès des pots-de-vin instruit actuellement par la cour d'assises du Nord du Caire et impliquant, entre autres, le directeur du Fonds de développement culturel, Ayman ${ }^{\mathrm{C} A b d}$ al-Muncim, le directeur du Fonds de sauvetage des monuments nubiens, Husayn Ahmad Husayn, et le président de l'administration architecturale au sein du Conseil Suprême des Antiquités (CSA), 'Abd al-Hamîd Qutb, ce procès, disions-nous, en est la meilleure illustration. Mais tout en respectant la présomption d'innocence et au-delà des considérations morales, de l'euphorie des uns et du catastrophisme des autres, un constat s'impose : jamais auparavant on n'a restauré un aussi grand nombre de monuments à la fois, ni aussi vite. Fondé au $X^{e}$ siècle et inscrit en 1979 sur la Liste du patrimoine mondial de I'Unesco, Le Caire islamique est un chantier démesuré : 850 millions de livres égyptiennes, cent soixante-trois monuments concernés en trois phases. Les critiques qui fusent de partout - à tort ou à raison, ce n'est point notre sujet ici - ne parviennent pas à ralentir 
la cadence effrénée imposée par le ministère de la Culture et le CSA. II ne se passe pas de semestre sans que soient inaugurés un ou plusieurs monuments.

Très vite, le CSA passe de la question du comment conserver à celle du pourquoi de la conservation. La restauration n'étant pas une finalité en soi, à quoi donc peuvent bien servir tous ces monuments fraîchement réhabilités ? Les remettre sous clé, c'est les condamner, à coup sûr, à un retour à la case départ. Il ne faut jamais s'arrêter à la restauration des édifices historiques, puis les abandonner à leur sort. Seule une réutilisation judicieuse et respectueuse de leur caractère historique ou architectural pourrait garantir leur pérennité. Mais comment? À quel dessein ? Si la conservation du patrimoine est devenue, depuis pas moins de deux décennies, I'affaire de tous en Occident, il convient de reconnaître que l'Égypte accuse un retard considérable sur cette problématique. Pourtant, celle-ci suscite à l'étranger des études, des groupes de réflexion, des colloques qui permettent d'échanger les connaissances et les expériences, et des commissions associant tous les acteurs du patrimoine (architectes, bureaux d'études, laboratoires, artisans, entreprises, réseaux associatifs). Car la réaffectation des monuments n'est pas une hérésie moderne. Depuis toujours, on a fait du neuf avec du vieux. Dans I'absolu, on peut même prétendre que tout est réutilisable : une abbaye, un temple, une citadelle, un hammam, une friche industrielle, etc. Au fil des siècles, les monuments égyptiens ont servi d'entrepôts, de silos, de magasins d'artillerie, d'abris antiaériens, d'usines, de garnisons... Les coptes ont transformé les temples pharaoniques en chapelles, les tables d'offrande en autels. Les musulmans ont procédé de même à leur tour. Au lendemain de la révolution du 23 juillet 1952 et de ses tornades de confiscations et de nationalisations tous azimuts, combien de villas coloniales et de palais princiers se sont métamorphosés en entrepôts, filatures, écoles gouvernementales, hôpitaux publics, sièges et permanences de I'Union socialiste (unique parti officiel au pouvoir, ancêtre de l'actuel Parti national démocratique, PND)!

Fort heureusement, les choses ont radicalement changé depuis. Les spécialistes ont élaboré plusieurs traités, conventions et chartes internationales (Athènes 1931, Venise 1965) définissant quelques principes qui président à la conservation et à la restauration des monuments et des sites. Chaque État signataire est désormais tenu de les appliquer dans le cadre de sa culture et de sa tradition. Car la meilleure garantie de conservation des œuvres d'art découle du respect et de l'attachement des peuples eux-mêmes à leur propre histoire. Le présent article s'attache à décrypter la politique de réaffectation (icâat tawzîf) des monuments historiques à des fins didactiques, culturelles ou artistiques mise en place en Égypte entre 2000 et 2008. Dans ce dessein, nous avons sélectionné dix-sept spécimens très variés : neuf palais, trois demeures bourgeoises, deux fontaines publiques, un caravansérail, une école coranique et une citerne. Parmi ceux-ci, certaines réaffectations sont déjà achevées, connaissent un franc succès 
ou un échec en demi-teinte, d'autres sont en cours, d'autres encore n'en sont qu'à leurs balbutiements. Pour chacun de ces cas situés aussi bien au Caire qu'en Alexandrie ou en province, nous présenterons une notice portant sur la description sommaire du monument et de son fondateur, la nature et les circonstances de sa transformation et une évaluation succincte du résultat final. Mais auparavant, il convient de rappeler quelques fondamentaux.

La réaffectation d'un monument est systématiquement précédée d'études archéologiques et historiques, de travaux de restauration architecturale minutieuse, voire parfois de fouilles. Souvent, elle nécessite l'assainissement et la remise aux normes de toute l'infrastructure vétuste (réseau électrique, canalisations d'eau potable et d'égout qui affectent considérablement l'équilibre de la nappe phréatique). En cours de route, il n'est pas rare de buter sur des imprévus qui impliquent des dépassements de crédits et de délais. Bref, c'est un cheminement lent et ingrat, qui peut durer plusieurs années. Celui qui initie un tel projet n'est pas forcément le même qui, le moment venu, coupera le ruban inaugural, gravera son nom sur la plaque commémorative et en cueillera les lauriers. Par conséquent, ceci exige des responsables une bonne dose d'abnégation et une vision à moyenne et à longue portées. Vision qui peut être biaisée par des échéances électorales, des visées carriéristes ou des ardeurs propagandistes, qui s'inscrivent souvent dans le très court terme. Le temps de la politique n'est pas le temps de l'archéologie. Le premier est pressé, inconstant, zappeur... Le second patient, persévérant, stable... Songez, par exemple, que la restauration de Bayt al-Harrâwî a nécessité pas moins de sept années entre 1986 et 1993, le concours de différents organismes scientifiques égyptiens et français, et l'intervention de plusieurs centaines d'ouvriers et de professionnels : restaurateurs, ingénieurs, architectes, menuisiers, tailleurs de pierre, maçons, etc. Il s'agit en plus d'un processus extrêmement onéreux. Rien que pour les quinze cas mentionnés dans cet article, cela représente un coût de près de 300 millions de livres égyptiennes. Dans un pays en voie de développement comme l'Égypte, où plus de $40 \%$ de la population vit au-dessous du seuil de pauvreté avec moins de 2 dollars par jour, allouer de telles sommes à l'entretien des « vieilles pierres » peut être considéré comme un luxe indécent.

Outre son coût exorbitant, chaque projet de restauration doit être dûment étudié sous toutes les coutures, dans la mesure où on ne peut pas réitérer à I'infini ce genre de lifting. Or, les observateurs constatent aujourd'hui qu'avant chaque intervention, le CSA commence souvent par ôter les traces des restaurations précédentes jugées erronées, voire néfastes. Ces restaurations antérieures, décriées aujourd'hui, avaient pourtant été implantées soit par le CSA lui-même, soit, surtout, par le Comité de conservation des monuments de I'art arabe qui, au début du XXe siècle, avait réalisé des travaux gigantesques. Bien entendu, nul ne peut garantir que les nouvelles « re-restaurations » ne seront pas pareillement mal jugées à l'avenir ! Quoi qu'il en soit, il s'agit là 
d'un cercle vicieux qui n'est pas sans danger. Car, bon an, mal an, ces interventions répétées laissent des stigmates indélébiles sur les monuments et ne sont pas toujours aussi réversibles qu'on le croit. De même, la réutilisation d'un monument implique de nombreux paramètres, des installations spécifiques et des contraintes techniques dont il faut absolument tenir compte dès le début du projet de revalorisation. Restaurer d'abord, on verra plus tard : ce n'est guère une conduite avisée. II est aberrant d'attendre l'issue des restaurations pour enfin commencer à réfléchir à une éventuelle utilisation. Ce fut le cas, par exemple, de Bayt al-Harrâwî - une expérience pionnière en la matière qui a servi de champ d'expérimentation - et du Sabîl Muhammad 'Alî dont nous parlerons en détail plus loin.

Les interventions sur le patrimoine entraînent souvent des conflits sociaux et juridiques avec les propriétaires, les locataires ou les squatteurs des bâtiments historiques. En Égypte, la notion de patrimoine n'est pas bien intégrée dans les lois d'urbanisme et de la construction. Il est toujours difficile de concilier le droit public et les droits des particuliers vivant dans le voisinage des monuments. L'État ne disposant pas de ressources nécessaires pour dédommager correctement les expropriations et les transferts forcés et parfois massifs de population, les projets de revalorisation s'implantent souvent dans un climat défavorable. Ils ne suscitent guère l'adhésion ni le concours d'une frange importante de la population qui, par ricochet, devient méfiante et hostile à la réhabilitation de son environnement. Dans le meilleur des cas, les gens ne se sentent pas du tout concernés. Rappelons qu'il a fallu quelques décennies, le concours de plusieurs ministères, quatre morts à $\mathrm{Nag}^{\mathrm{C}}$ al-Târif en 1998 et 180 millions de livres égyptiennes pour parvenir à évacuer manu militari, début décembre 2006, les trois mille deux cents familles vivant dans huit cents maisons traditionnelles à al-Qurna, la plus grosse agglomération de la rive ouest de Louqsor. Certes, une grande partie de ces vingt mille habitants ont été relogés vaille que vaille dans des maisons en béton construites quelques kilomètres plus loin dans le nouveau village al-Târif. À présent, les archéologues peuvent fouiller toute la nécropole, mais à quel prix! Le mégaprojet de réaménagement de la ville de Louqsor, mené tambour battant et qui a coûté jusqu'à présent la bagatelle de 1,2 milliard de livres égyptiennes, ce mégaprojet génère les mêmes répercussions : déracinement, exil, perte d'emploi, détérioration de la qualité de vie, etc. À la sortie de la prière communautaire du vendredi 28 mars 2008, près de trois mille émeutiers saccagent plus de vingt-cinq bazars touristiques, arrachent des arbres, démolissent la façade du Centre $d^{\prime}$ information touristique ainsi que quatre-vingt-douze projecteurs. ${ }^{1}$

1. Akhbâr al-Yawm 29 mars 2008, Al-Wafd, 29 mars 2008, Al-Ahrâm, 29 mars 2008, Al-Akhbâr, 30 mars 2008, The Egyptian Gazette, 30 mars 2008, Daily News Egypt, 30 mars 2008. 
Ils entendent protester contre l'expropriation et la démolition de leurs maisons contiguës aux temples de Karnak. Les blindés des forces de sécurité parviennent à maîtriser les échauffourées qui se sont soldées par vingt-cinq arrestations. On le voit bien, lorsque toute cohabitation est jugée impossible entre les individus et leur patrimoine, lorsque aucun compromis n'est envisageable, il ne reste plus que la vivisection. "Le Conseil suprême des antiquités ne sacrifiera pas les monuments qui constituent un patrimoine irremplaçable, alors que les êtres humains naissent, meurent et se reproduisent », statue le secrétaire général du CSA, Dr Zâhî Hawwâs. ${ }^{2}$

En matière de patrimonialisation, deux approches radicalement antagonistes s'affrontent aujourd'hui dans le contexte égyptien et aboutissent à des résultats diamétralement opposés. La première approche inscrit le facteur humain au coeur d'une équation dans laquelle l'Homme et son passé ne font qu'un. L'intégration et le ralliement des riverains à tout projet de sauvegarde archéologique sont dès lors indispensables. Car rien ne peut réussir ni perdurer sans leur assentiment. Encore moins contre leur gré. Partout où il intervient, I'Aga Khan Trust for Culture (AKTC) incarne par excellence cette approche profondément humaniste et clairvoyante. Dans le quartier défavorisé d'al-Darb al-Ahmar, par exemple, il conjugue les restaurations avec le développement du niveau social et économique des habitants. Micro-crédits, lutte contre le chômage, stages d'initiation, programmes d'apprentissage et de formation professionnelle, réaffectation des édifices à des fins éducatives et sociales : large est la panoplie mise au service d'une vision globaliste, qui considère que chaque projet de préservation se doit d'avoir une dimension socioéconomique. L'intérêt des monuments et celui des habitants ne sont pas inconciliables. Certes, I'AKTC aurait pu se contenter de fouiller et de restaurer la muraille ayyubide du Caire, ainsi que quelques mosquées et demeures archéologiques situées à al-Darb al-Ahmar. Dès 1997, I'AKTC a commencé à transformer des monticules de décharge accumulés depuis six siècles en un immense parc de soixante-seize feddans, un nouveau poumon pour une ville asphyxiée.

La seconde approche fait totalement abstraction du facteur humain. Elle considère les bâtiments historiques comme de simples grains de beauté éparpillés sur un visage hideux, ou des électrons libres qui gravitent autour d'un noyau urbain décousu au bord de l'implosion. Elle perçoit les riverains non pas comme des alliés précieux vivant en symbiose avec les monuments, mais comme des parasites, trop gueux, pas assez civilisés et, surtout, foncièrement nuisibles pour le patrimoine. Cette vision étriquée n'embrasse aucun lien entre le monument et son environnement naturel et humain, et manque d'appréhension globale des espaces. Elle clive au lieu de fédérer et fait rimer

2. Al-Musawwar, $1^{\text {er }}$ décembre 2006. 
réhabilitation avec expulsion. Elle transforme les lieux palpitants de mémoire en nature morte. En Disneyland pour vacanciers pressés. Mais, une fois exsangue de ses milliers d'habitants, de commerçants et d'artisans jugés indésirables, une fois dépourvu de ses cris, de ses couleurs et de ses odeurs qui lui donnent un cachet si particulier, une fois envahi par les stands de glaces, les vendeurs de cartes postales, les bureaux de change et les galeries marchandes sans âme, que deviendra le cœur médiéval de la ville du Caire ? Un paysage de cartonpâte. Un décor de pacotille. Un paradis artificiel pour touristes low-cost. Cette "muséification» cauchemardesque si peu respectueuse des humains et du patrimoine n'est même pas rentable sur le plan mercantile. Car les touristes en mal d'authenticité et un tantinet cultivés ne se laisseront jamais prendre dans un piège aussi grossier.

Une autre difficulté, et non des moindres : en matière de réaffectation, il n'y a pas pléthore de débouchés. Chaque bâtiment ancien a sa nature et son environnement propres, qui en déterminent et limitent les perspectives de réutilisation, et les nouvelles fonctions qu'il est susceptible d'accueillir. Centres de culture, de documentation, d'apprentissage artisanal, ateliers d'art ou d'informatique, bibliothèques, musées, salles d'exposition ou de conférences : telles sont les réutilisations tolérées et encouragées aujourd'hui par le ministère de la Culture. Activités qui distraient, éduquent et rendent d'éminents services aux usagers. Mais activités si peu lucratives. En tout cas, elles ne favorisent pas de retour sur investissement, ni même l'indépendance, l'autofinancement ou la maintenance du monument ainsi réutilisé. Certains modes de réutilisation fructueuse mis en place à l'étranger ne font pas recette en Égypte. Le CSA refuse, par exemple, I'utilisation de l'amphithéâtre romain de Kom al-Dikka en Alexandrie pour organiser des spectacles musicaux ou théâtraux, à l'instar du Festival international de Baalbek au Liban ou celui de Jerash en Jordanie. Face à ce refus et à la compétition touristique de plus en plus acharnée entre l'Égypte et certains de ses voisins arabes, le président du Conseil suprême de Louqsor, Samîr Farag, propose une alternative juteuse. Utiliser l'esplanade du temple de Lougsor pour la tenue d'un festival annuel de musique à partir de 2009, sous le haut patronage de $\mathrm{M}^{\mathrm{me}}$ Suzanne Moubarak. ${ }^{3}$ Pourquoi écarter l'amphithéâtre de Kom al-Dikka avec ses volées de gradins étagés qui procurent une bonne vision à un maximum de spectateurs et ses qualités acoustiques exceptionnelles pour les spectacles de plein air, et promouvoir des sites étrangers à cette fonction ? Pourtant, ces mêmes théâtres antiques assurent aujourd'hui le succès phénoménal des festivals d'opéra, d'art lyrique, de musique classique et des férias partout dans le monde, que ce soit en Grèce ou bien dans les villes d'Orange et d'Arles.

3. Al-Usbû́, 26 janvier 2008. 
Il faut rappeler que les six représentations de I'inoxydable opéra Aïda du grand compositeur italien Giuseppe Verdi (Dayr al-Baharî en 1987, 1994, 1997 ; plateau de Gîza en 1998, 1999, 2002) ont lieu sur une immense plateforme installée devant le monument et non pas à l'intérieur de celui-ci. Le temple $d^{\prime}$ Hatchepsout, les pyramides et le Sphinx servent uniquement de toile de fond, de mise en scène et de décors naturels du spectacle. II ne s'agit donc pas d'une réaffectation sérieuse du monument. Car celui-ci n'est pas au cœur de l'événement, mais sert tout juste d'alibi, de prétexte, de faire-valoir, comme dans les spectacles son et lumière. Le Dr Zâhî Hawwâs précise :

«Je ne suis pas contre ces événements importants pour le tourisme en Égypte [...]. Mais il faudrait prendre des mesures de précaution et interdire qu'ils aient lieu à l'intérieur des monuments. Le site peut simplement servir de toile de fond ${ }^{4}$

Malgré cette utilisation volontairement minimaliste, chacune des représentations d'Aïda a étéle théâtre d'une passe d'armes entre partisans inconditionnels (responsables du tourisme, voyagistes) et détracteurs farouches (archéologues, égyptologues) de ces shows fortement médiatisés et de l'exploitation des sites archéologiques à des fins touristiques, artistiques et lucratives. ${ }^{5}$ Menace pour la sécurité, atteinte au caractère " sacré » du site et à sa " dignité ", hurlent les uns. Promotion du bel canto, plaisir des mélomanes, attraction des touristes du monde entier, ripostent les autres. L'ex-doyen de la faculté d'archéologie du Caire, Dr Salâh al-Buhayrî, en appelle à :

« [...] I'interdiction des festivités célébrées au sein des sites archéologiques, vu leurs effets néfastes, notamment I'utilisation des enceintes acoustiques et des rayons laser ».

Avis partagé par le Dr 'Abd al-Halîm Nûr al-Dîn, ex-secrétaire général du CSA, qui estime que «le CSA a suffisamment de budget pour ne pas lorgner les retombées financières de ces festivités ». En outre, il attire l'attention sur la nécessité de respecter les lieux et les us et coutumes égyptiens : " II faudra interdire la consommation d'alcool aux nombreux étrangers qui fréquent ces festivités ». ${ }^{6}$ Le Dr Ahmad al-Sâwî, professeur d'archéologie islamique et exdoyen de la faculté de lettres de Suhâg :

«[...] refuse catégoriquement la tenue de telles festivités... Ni le ministre de la Culture, ni le CSA ne peuvent en disposer de la sorte. Car le patrimoine archéologique n'est pas leur propre propriété, mais celle du peuple égyptien tout entier ».

4. Al-Ahram Hebdo, 28 mars 2001.

5. Al-Akhbâr, 29 août 2001, Al-Ahram Weekly, 6 septembre, Al-Wafd, 15 septembre 2001.

6. Al-Ahrâr, 29 mars 2001. 
Enfin, le Dr 'Alî Radwân, président de I'Union des archéologues arabes, considère ces festivités comme un sacrilège :

«En agissant ainsi, nous rabaissons notre patrimoine. Qu'importe les sommes d'argent drainées par ces activités. Nous devons plus de respect à notre propre patrimoine qu'à l'argent gagné de la sorte ».?

$\mathrm{S}^{\prime} \mathrm{il}$ ne cache guère son hostilité au tourisme de masse et à ses effets néfastes sur les monuments, le Dr Hawâss émet, toutefois, un distinguo subtil : oui aux spectacles "policés » (opéra Aïda, musique classique), non aux grandes kermesses indisciplinées (compétition sportive, concert pop). Pourtant, une ribambelle d'artistes hétéroclites ne cesse de se produire sur le plateau quatre fois millénaire de Gîza : le compositeur de musique électronique Jean-Michel Jarre (concert du millénaire 1999-2000), la papesse colombienne de la pop très sexy Shakira (28 mars 2007), la Montréalaise d'origine égyptienne Chantal Chamandy (7 septenbre 2007), les rappeurs français d'IAM (14 mars 2008), etc. À chaque fois, le site archéologique ainsi que tout le quartier sont littéralement pris d'assaut par des milliers de spectateurs plus ou moins déchaînés. Les nuisances sont telles que certains riverains ont créé une nouvelle association intitulée Humât al-ahrâmât (les défenseurs des pyramides). Fondée par l'avocat Shâhîn Abû al-Futûh, cette association regroupe des personnalités de tous bords mobilisées pour la sauvegarde des pyramides. ${ }^{8}$ Enfin, soulignons qu'en matière d'opéra, les responsables égyptiens font preuve de peu d'éclectisme. Ä̈da, composé d'après une intrigue de l'égyptologue Auguste-Édouard Mariette, demeure l'unique opera seria (opéra sérieux) qui, au cours des deux dernières décennies, trouve grâce aux yeux du ministère de la Culture. Manque d'imagination et d'ouverture ? S'il faut absolument s'en tenir aux opéras égyptisants et au genre héroïque ou tragique, pourquoi pas La Flûte enchantée de Mozart, Orantea de Cavalli ou Orphée et Eurydice de Gluck? Une chose est sûre : ce répertoire ne risquerait pas de s'élargir à une opera buffa (opéra comique), encore moins à une opérette d'Offenbach.

Prenons deux autres exemples de modes de réaffectation décriés en Égypte. Lorsque le président de I'Organisme général du livre, Dr Nâsir al-Ansârî, propose d'organiser au cours de l'été 2006 un salon international du livre arabe dans le fort de Qâytbây en Alexandrie, il se heurte au refus quasi général des intellectuels. ${ }^{9} \mathrm{D}^{\prime}$ aucuns craignent que l'affluence des visiteurs attirés par ce type de manifestation ne soit préjudiciable au monument. D'autres y voient une atteinte morale à la majesté de cet édifice vénérable, chargé d’histoire et qui ne sied guère à la commercialisation, fussent des livres. Cet exemple trahit bien une vision trop «sanctifiée » ou "sacralisée » du patrimoine et l'acuité

7. Akhbâr al-Adab, $1^{\mathrm{er}}$ avril 2001.

8. Rûz al-Yûsif, 29 septembre 2007.

9. Al-Ahrâm, 30 avril 2006. 
des barrières psychologiques et morales dressées contre sa réutilisation. Sur le lien privilégié entre monuments et belles-lettres, citons un autre cas intéressant. Il s'agit de la décision de transformer le Sabîl-kuttâb Abû al-Iqbâl, fontaine publique fondée en 1125/1713 et située à al-Ghûriyya, en siège de la section égyptienne du PEN Club international. Fondée en 1921, cette association apolitique et non gouvernementale basée à Londres a pour but de rassembler des écrivains de tous pays attachés aux valeurs de paix, de tolérance et de liberté, à travers notamment des congrès et des échanges culturels internationaux. D'illustres écrivains comme Tâhâ Husayn, Tawfîq al-Hakîm ou Nagîb Mahfûz se sont succédé à la tête du PEN Club égyptien. Celui-ci a soutenu, entre autres, le poète Ahmad al-Shahâwî, la romancière Nawâl al-Sachâwî ou le théologien libéral Nasr Hâmid Abû Zayd dans leurs démêlés avec la censure politico-religieuse. Mais, aujourd'hui, le PEN Club égyptien connaît d'énormes difficultés, dont la plus aiguë est la quête d'un siège permanent. C'est bien dommage que l'excellente idée de son installation dans le Sabîl-kuttâb Abû al-Iqbâl n'ait pas été suivie d'effet.

Contrairement à d'autres pays musulmans comme la Tunisie, le Maroc, la Syrie ou la Turquie, la réutilisation des monuments historiques comme restaurants ou lieux d'hébergement touristique est strictement bannie en Égypte pour des motifs religieux : consommation d'alcool, piscine mixte, nudité, licence des mœurs, casino et jeux d'argent... Pourtant, ce type d'établissements assure parfaitement l'entretien régulier et permanent des édifices et dégage de gros bénéfices susceptibles de financer d'autres projets de réhabilitation sans alourdir le budget de l'État. Si la course au profit n'est pas l'unique critère d'un projet de réutilisation, pourquoi faire systématiquement la moue aux possibilités de rentabilité ? Pourquoi ne pas couper, une bonne fois pour toutes, le cordon ombilical qui rattache les monuments au Fonds de développement culturel, la boîte de Pandore du ministère de la Culture ? En France, des hôtels de caractère ont été aménagés dans des maisons ou des monuments historiques : abbayes, châteaux forts, manoirs, couvents royaux. Ces établissements d'exception sont gérés par des sociétés spécialisées comme France Patrimoine ou Installation Hôtelière. Ils allient confort, charme et tradition, et disposent de toutes les facilités pour la tenue de séminaires, banquets, congrès, mariage, etc.

En janvier 2007, le ministre de la Culture révèle son intention de louer à une chaîne hôtelière Wakâlat Qâytbây, fondée en 885/1480 et située à Bâb al-Futûh. Cette annonce stupéfiante déclenche un tollé, bien que Farûq Husnî I'ait assortie de deux conditions draconiennes: prohiber la consommation d'alcool et l'aménagement de piscine afin de respecter le caractère religieux du Caire historique, conformément à la loi sur le tourisme qui interdit ce genre d'activités au sein des zones archéologiques religieuses. ${ }^{10}$ Pourtant, la réuti-

10. Al-Musawwar, 26 janvier 2007, Akhbâr al-Yawm, 3 février 2007. 
lisation de ce caravansérail en hôtel n'a rien d'extraordinaire puisqu'il était destiné, dès l'origine, à l'hébergement pour une durée plus ou moins longue des pèlerins, des voyageurs, des marchands itinérants et aux transactions commerciales. Faire de la prohibition une condition sine qua non de la réutilisation du patrimoine embrouille inextricablement la situation, car sans Licence IV, aucun établissement hôtelier ou restaurant n'est viable. L'ex-président du secteur des Antiquités islamiques, $\mathrm{Dr}{ }^{\mathrm{C}} \mathrm{Abdallah}$ Kâmil, s'oppose catégoriquement à l'idée de transformer Wakâlat Qâytbây en hôtel touristique. Il dénonce : « [...] ce genre de projets décrétés en haut lieu. Il faut fixer des limites à tous ces projets mis en place sans étude préalable et à l'insu du Comité permanent du CSA. Ces projets de réexploitation comportent des menaces extrêmement dangereuses, qui peuvent se manifester à long terme. Ceci affecte naturellement le monument qui n'est pas prévu pour accueillir autant de personnes. [...] Les projets de réutilisation des sites historiques doivent être décidés par une commission ad hoq, en tenant compte de la vocation originelle de chaque site».

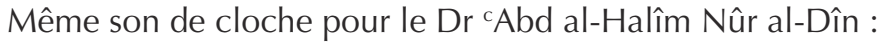

«Nous ne sommes pas en Europe pour s'assurer que les usagers vont prendre soin du monument. Qui pourrait garantir la conservation de celui-ci une fois transformé en hôtel avec l'infrastructure indispensable (chambres, services, restaurants, salles de bains, etc.) ? L'aspect architectural sera nécessairement modifié. On pourrait même perdre totalement l'édifice ».11

Les exemples précédents montrent à quel point le réaménagement d'un monument doit impérativement ménager d'abord les traditions et les croyances religieuses. D'ailleurs, la réticence des théocraties arabes à réaffecter les lieux cultuels à des fins culturelles n'est un secret pour personne. Les églises et les mosquées sont entourées d'un halo de sacralité qui empêche leur utilisation dans des spectacles artistiques ou culturels, vecteurs de mixité entre les deux sexes. Sans parler du dédain des fondamentalistes musulmans pour la musique profane, la sculpture, la peinture et les arts figuratifs en général. Concert de la chanteuse islandaise Björk à la Sainte Chapelle, récital d'orgue dans la basilique du Sacré-Cœur à Montmartre, concert de musique populaire dans la cathédrale Notre-Dame de Paris, etc. : la patrimonialisation à la française est loin de faire des émules ici. Le must pour les uns peut légitimement inspirer un rejet brutal et une répulsion épidermique aux autres. Il n'y a pas de panacée archéologique ni de Graal. Autrement dit, il est tout à fait normal que chaque société puisse définir elle-même le parti à prendre dans la réutilisation et la mise en valeur de son propre patrimoine.

11. Akhbâr al-Adab, 11 février 2007. 


\section{PALAIS HISTORIQUES}

\section{Palais Fâtima Haydar : musée des Bijoux royaux}

Situé à Zîzinyâ à l'est d'Alexandrie, le qasr al-mugawharât (château des bijoux) a été fondé en 1919 par Zaynab hânim Fahmî et achevé en 1923 par sa fille Fâtima al-Zahrâ', alias Fâtima Haydar, arrière arrièrepetite-fille d'Ibrâhîm pacha, fils de Muhammad 'Alî. II a été nationalisé au lendemain de la révolution du 23 juillet 1952. Mais, Fâtima Haydar

bénéficiera tout de même du privilège 1. Palais Fâtima Haydar

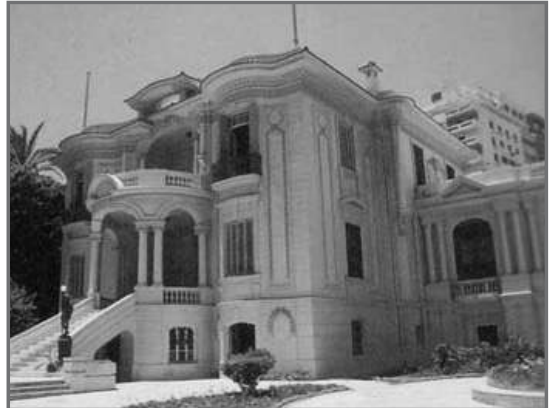
d'occuper son propre palais jusqu'en 1964, date à laquelle il fut définitivement cédé au gouvernement égyptien. Cette demeure néo-classique de $4185 \mathrm{~m}^{2}$ servira alors de résidence présidentielle jusqu'à sa transformation en musée en 1986 par décret présidentiel $\mathrm{n}^{\circ}$ 173. Deux architectes ${ }^{\mathrm{C}}$ Alî pacha Fahmî et Antonio Lasciac ont conçu ce palais de deux étages composé de deux ailes est-ouest reliées par une galerie et entouré d'un vaste jardin. Ils feront venir d'Italie artisans, peintres et sculpteurs pour réaliser les enrichissements décoratifs particulièrement chargés de styles baroque et rococo, les magnifiques plafonds ornés de peintures de style Renaissance et les vitraux de style romantique.

Au terme d'un projet de réaménagement, le CSA inaugure en février 1994 le musée des Bijoux royaux placé sous la direction de Sâmya al-cÂmûdî. II est équipé de systèmes d'éclairage, de vidéosurveillance, de sécurité, de climatisation et d'alerte contre les incendies visant à protéger sa collection d'objets précieux, bien conservés et exposés dans des vitrines modernes. On y trouve des bijoux et des objets fascinants ayant appartenu à la famille royale, depuis Muhammad 'Alî jusqu'au roi Fârûq (1805-1952) : épée, boîte de nushûq (tabac à priser) et jeu d'échecs de Muhammad 'Alî sertis de pierres précieuses, colliers, bracelets, boucles d'oreilles, broches en or avec perles de culture et rubis, vaisselle en or incrustée de diamant, tasses de thé en porcelaine, médailles en or incrustées de 288 diamants, horloges, portraits de la famille royale, etc. Parmi les pièces maîtresses figurent la couronne en platine ornée de 2159 diamants et onze perles de culture appartenant à la princesse Shwîkâr, première épouse de Fu'âd $1^{\mathrm{er}}$, ainsi que la couronne en platine en forme de fleurs serties de 1506 diamants avec une broche ayant appartenu à la reine Farîda.

* Pour toutes les photographies sauf mention contraire, crédits: Aymé Lebon. 
Mais suite à l'effondrement de l'une de ses salles, ce musée est fermé au public depuis le 24 janvier 2003, soit à peine neuf ans après sa mise en service. Le CSA y entreprend des travaux de restauration et de réaménagement global dont le coût s'élève à 50 millions de livres égyptiennes. La fermeture simultanée, et pour une période prolongée, du musée des Bijoux royaux et du Musée gréco-romain a soulevé une vague de protestation dans les milieux archéologiques et touristiques. La politique du CSA de création et de modernisation des musées existants pose, en effet, de nombreux points d'interrogation. Il faut dire que près de la moitié des musées égyptiens sont actuellement hors service. C'est le cas, par exemple, des musées d'Art islamique, des Carrosses royaux, des Bijoux royaux à la Citadelle du Caire et de ceux de Port-Saïd, de Tantâ, d'Aswân ou de Mallawî. Sans parler des musées en cours de construction comme le Grand Musée égyptien, le musée national de la Civilisation, les musées des portails du Caire historique et de la monnaie à la Citadelle du Caire, ou ceux de Rosette, de Sharm al-Shaykh, d'Hurghada, de Kafr alShaykh, de Suez, de Suhâg, du musée des crocodiles à Kûm Umbû et du musée Atonien à Minyâ.

\section{Palais Ascad Pacha Bâsîlî : musée national d'Alexandrie}

C'est à Ascad Pacha Bâsîlî, célèbre négociant en bois, d'origine grecque, que I'on doit la construction en 1929 de cet imposant palais d'une superficie de $1650 \mathrm{~m}^{2}$, situé en plein centre-ville d'Alexandrie. La crainte des nationalisations a incité ses héritiers à le vendre en 1954 au consulat des États-Unis. En 1996, le ministère de la Culture I'a racheté pour la somme de 12 millions de livres égyptiennes.

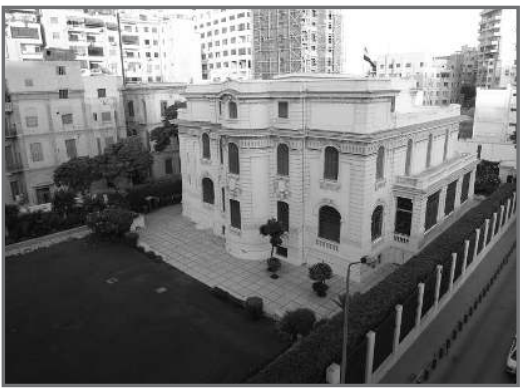

2. Palais $A s^{c}$ ad Pacha Bâsîlî. Un homme d'affaires en avait proposé 30 millions, mais les Américains ont préféré le vendre au CSA qui s'était engagé à préserver l'intégrité architecturale du bâtiment en le transformant en musée. Le projet, lancé en janvier 2002, a coûté environ 24 millions de livres égyptiennes. Avec un étourdissant brio, le designer italien Maurizio De Paulo y a créé une exposition extraordinairement sophistiquée, composée de vitrines suspendues et d'un système d'éclairage ultramoderne, utilisés pour la première fois en Égypte.

Placé sous la direction d'Ibrâhîm Darwîsh, le musée national d'Alexandrie abrite plus de mille huit cents pièces archéologiques appartenant aux différentes époques pharaonique, grecque, romaine, copte et islamique. Les collections ont été sélectionnées dans les entrepôts et les principaux musées d'Égypte, en plus de cent soixante-sept pièces inédites provenant des fouilles sous-marines. Le sous-sol du palais - servant d'abri antiaérien lors de la 
Deuxième Guerre mondiale - a été transformé en laboratoire de restauration. L'annexe, utilisée autrefois comme garage, a été convertie en entrepôts et en salle de conférences d'une capacité de cent cinquante places. Une cafétéria a été aménagée sur le toit. Un théâtre en plein air de près de mille places a été installé dans le jardin $\left(900 \mathrm{~m}^{2}\right)$ à l'arrière du bâtiment pour des activités culturelles. Après son inauguration en grande pompe par le président Moubarak, le Premier ministre et plusieurs membres de son gouvernement le 31 août 2003, le musée national d'Alexandrie a été aussitôt fermé au public pour parachever le processus d'exposition. Un véritable esclandre pour les agences de tourisme qui ont déjà programmé la visite du musée dans leurs excursions. Finalement, le musée sera "ré-inauguré » le 4 octobre 2003 par le ministre de la Culture, accompagné de l'ex-gouverneur d'Alexandrie, 'Abd al-Salâm al-Mahgûb et de I'actuel secrétaire général du CSA.

Trois petites remarques restent à faire sur ce beau projet réalisé en un temps record. Convertir ce bâtiment de deux étages avec ses vingt-cing salles en musée archéologique n'était pas une tâche facile. Certes, il est moins onéreux et plus facile de construire et d'équiper un nouveau musée que de transformer une demeure classique. Mais, dans ce cas-ci, le jeu en valait la chandelle. Avec la fermeture du musée des Bijoux royaux depuis 2003, puis celle inopportune du Musée gréco-romain pour au moins trente mois, le musée national d'Alexandrie est à présent le seul grand musée archéologique ouvert dans la seconde capitale. La deuxième remarque porte sur la création de nouveaux musées qui ne doit pas se faire au détriment de ceux déjà existants. Autrement dit, extirper des pièces méconnues des oubliettes des entrepôts archéologiques disséminés sur tout le territoire, les réunir et les exposer dans de nouveaux écrins est une politique tout à fait louable. Ceci n'a rien à voir avec la pratique dommageable, qui consiste à siphonner et à dépouiller les musées existants de leurs plus belles pièces, à fragmenter et à disperser ainsi leurs collections au profit des nouveaux musées. Enfin, la troisième remarque concerne la précipitation, maintes fois relevée, à inaugurer dans un grand battage médiatique un projet archéologique encore inachevé, quitte à le clore immédiatement après. Il s'agit là d'un syndrome de l'interférence des champs politiques et archéologiques. Cette confusion des genres est, certes, difficile à éluder, car lorsque l'on parle d'Histoire et de mémoire, la politique n'est jamais bien loin. Lorsque tous les indicateurs sont dans le rouge, quoi de mieux que l'archéologie pour servir de marqueur politique, d'outil de communication ? Toutes les inaugurations et les tournées d'inspection des grands chantiers archéologiques sont systématiquement placées sous les auspices du président Moubarak et/ ou de la First Lady, ou à défaut du Premier ministre et entourées d'un tam-tam médiatique. Mais, à trop vouloir respecter l'agenda d'un homme politique - ici en l'occurrence le chef de l'État - on en arrive à trop précipiter, voire bâcler des travaux archéologiques qui, eux, suivent un autre tempo et obéissent à une logique différente. 


\section{Palais de l'émir Sayf al-Dîn Tâz}

Le 15 mars 2002, de grands pans des murs arrière du palais de l'émir Sayf al-Dîn Tâz b. Qatghâg, I'un des princes influents à l'époque des Mamlûks Bahrî́n', s'effondrent et entraînent dans leur chute quelques dizaines d'habitations adjacentes. S'il n'y a pas eu de victime, les dommages architecturaux sont considérables, au point que cette date marque, en quelque sorte, la mort clinique de cette demeure mamelouke fondé en 753/1352 et située au

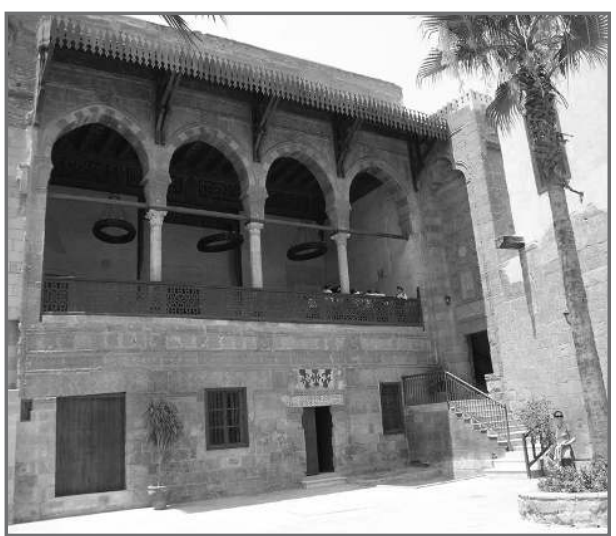

3. Palais de l'émir Sayf al-Dîn Tâz 27 rue al-Syûfiyya dans le quartier surpeuplé d'al-Khalîfa au Caire. Les premières inspections attribuent cet effondrement aux tas d'ordures accumulées par les riverains sur ce site abandonné et transformé progressivement en véritable dépotoir. L'étendue des dégâts est telle que certains experts, dépêchés sur place, estiment vaine toute opération de sauvetage. Ils n'hésitent pas à préconiser la démolition totale des vestiges, qui donnent au quartier un aspect déprimant et sont de véritables fléaux pour leur environnement. Toutefois, le CSA tente une opération urgente de sauvetage, de restauration et d'études sur la façon la plus appropriée de réhabiliter ce palais. Celui-ci avait déjà connu de nombreuses réutilisations : entrepôt de matériel militaire sous Muhammad cAlî, puis école de filles à la fin du XIXe siècle, avant de finir en dépôt principal du ministère de l'Éducation abritant plusieurs centaines de milliers de manuels, des pupitres et des dizaines d'épaves de cars de ramassage scolaire.

Il a fallu quatre ans de restauration intensive et 20 millions de livres égyptiennes pour réhabiliter ce vaste palais de plus de $8000 \mathrm{~m}^{2}$ de superficie. Celui-ci a été réparti en secteurs. Chaque secteur a été partiellement ou totalement démonté, isolé, consolidé, chemisé, voire carrément reconstruit. Les premières opérations de déblayage ont permis d'exhumer des milliers d'éléments architecturaux et décoratifs en bois, en métal et en pierre qui ont été fixés à leur emplacement d'origine. Les travaux de fouilles réalisés par le CSA ont conduit à quelques découvertes intéressantes : fontaine dans le $\mathrm{maq}^{c} \mathrm{ad}$ (salle de réception surélevée) du rez-de-chaussée, sâqiya (noria) au-dessus d'un puits destiné à arroser le jardin et à abreuver les animaux, colonne en

12. "Mamlûks Bahrî » était le nom donné à la garde du sultan Nagm al-Dîn Ayyûb (1240-49) dont la caserne se trouvait alors dans l'île de Rawda sur le Nil (Bahr), voir Encyclopédie de I'Islam, III, 1936, p. 230. 
marbre avec un chapiteau corinthien d'époque byzantine, citerne destinée à alimenter en eau le Sabîl 'cAlî Aghâ attaché au palais, canalisations en céramique...

Accompagnée du conseiller du Président Moubarak, Dr Usâma al-Bâz, et des ministres de la Culture et du Tourisme, $M^{\text {me }}$ Suzanne Moubarak inaugure le 11 octobre 2005 l'achèvement des restaurations du palais transformé en un centre de rayonnement culturel pour les habitants du quartier de la Citadelle. On y programme de nombreuses activités artistiques et culturelles, des débats sur l'actualité politique, économique ou sociale, des expositions de peinture et de photographie, des concerts de musique, des récitals de poésie et des représentations théâtrales destinées à promouvoir les jeunes talents. En outre, le palais accueille plusieurs troupes professionnelles grâce à la coopération tissée avec les différents centres culturels étrangers. Toutefois, le succès éclatant du palais de Tâz ne devrait pas occulter la pauvreté de programmation et le manque de substance des autres projets de réaffectation culturelle. En effet, le ministère de la Culture confie la gestion de ces nouveaux centres à des administratifs, qui ignorent tout de l'animation culturelle. II ne s'agit pas d'insuffisance de moyens, mais tout simplement de déficit d'imagination et de créativité. Pour porter tous ses fruits, I'affectation des monuments historiques à des fins culturelles doit être dévolue aux techniciens et aux spécialistes de l'animation et non pas à des ronds-de-cuir incapables d'insuffler la vie par manque d'ardeur et d'allant.

\section{Palais Mânistirlî : musée Umm Kulthûm}

Gouverneur du Caire en 1854 puis ministre de I'Intérieur en 1857, Hasan Fu'âd Pacha al-Mânistirlî, d'origines macédoniennes, fait construire en 1851 ce joyau architectural à l'extrême Sud-Ouest de la presqu'île de Rawda. En 1951, ce palais de $1000 \mathrm{~m}^{2}$ a été confisqué et classé monument historique par le gouvernement égyptien. Dans le cadre du projet de restauration du palais Mânistirlî, le ministère de la Culture décide, en avril 1998, de transformer I'une de ses annexes en un musée consacré à la chanteuse Umm Kulthûm (1898-1975), vingt-sept ans après sa disparition. Un excellent emplacement en bord du Nil à côté du nilomètre pour celle qui a longtemps chanté ce fleuve et dont la villa résidentielle de Zamâlik n'a pas longtemps résisté aux appétits des promoteurs immobiliers. Le ministère de la Culture confie à l'ingénieux designer italien Maurizio Di Paolo la conception de ce musée coquet, dont le coût s'élève à 7 millions de livres égyptiennes financées par le Fonds de développement culturel. Ce petit musée dernier cri de $250 \mathrm{~m}^{2}$, placé sous la direction du poète Ahmad 'Antar, est inauguré le 28 décembre 2001. Dans une atmosphère post-moderne, il expose dans huit vitrines quelques effets personnels emblématiques ayant appartenu à cette diva du monde arabe : huit robes cafetans assorties d'écharpes, chaussures, colliers, lunettes serties de diamants, gants Christian Dior, sacs à main, croissant en diamant, décora- 
tions, trophées, correspondances privées, manuscrits de chansons, différents contrats signés, etc. Sont également exposés divers phonographes, postes de TSF, projecteurs, disques vinyles et instruments de musique dont son célébrissime luth en bois de cèdre. Cette collection a été réunie grâce à la générosité de ses héritiers et de ses nombreux fans. On y trouve également une petite salle de projection et un écran ondulé de dix-neuf mètres qui retracent l'histoire de l'Égypte à travers les différentes étapes de la vie et de la carrière d'Umm Kulthûm et les nombreuses relations qu'elle entretenait avec tous les grands de ce monde. Le musée est doté d'une médiathèque et d'une bibliothèque qui présentent des extraits des six films qu'elle a tournés entre 1935 et 1948, des séquences sonores et audiovisuelles, une sélection de coupures de presse et d'ouvrages consacrés à celle que l'on surnommait "l'astre de l'Orient » (kawkab al-sharq).

Cette collection a pour ambition d'intéresser les admirateurs inconditionnels d'Umm Kulthûm, tout en donnant aux profanes l'opportunité de découvrir les différentes facettes de ce personnage devenu icône. Mais, au-delà de l'hommage rendu à la "Dame» dont le chant a rayonné sur le monde arabe tout au long du $X^{e}$ siècle, ce musée est également

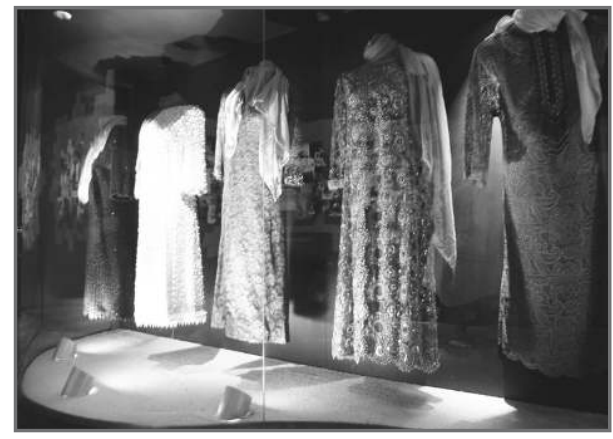

4. Palais Mânistirlî destiné à la tenue de concerts et de séminaires sur le patrimoine musical en coopération avec l'Opéra du Caire. Bref, un centre de création et de rayonnement musical. Mais dans les faits, toutes les célébrations culturelles importantes et les concerts de musique se tiennent à l'intérieur même du palais Mânistirlî. Le musée Umm Kulthûm reste figé, sclérosé et n'a pas du tout évolué depuis sa création. Une fois visité, ce $n^{\prime}$ est point la peine d'y retourner. Car il ne s'y passe absolument rien de nouveau. Certes, il s'agit-là d'une défaillance structurelle des musées égyptiens en général. Ils ne sont pas gérés comme des espaces vivants, évolutifs, de transmission de savoirs et d'émotions, entretenant la fièvre d'un public le plus large et le plus varié. Les musées égyptiens ne sont malheureusement pas des lieux de rencontre-débat, de dialogue des cultures, connectés aux principaux événements nationaux ou internationaux. Ils n'entretiennent point de liens assidus avec les différents visiteurs et ne leur offrent pas des formules diversifiées ni des parcours adaptés : enfants, adultes, adolescents, familles, groupes scolaires. Le musée Umm Kulthûm reste, malgré tout, un bel exemple perfectible de réutilisation, même s'il n'attire pas grand monde. S'il est décevant de dépenser tant d'argent pour si peu d'utilisateurs, le taux de fréquentation ne doit pas en revanche être l'unique critère d'évaluation d'une réaffectation. Surtout dans 
un pays où l'analphabétisme touche presque le tiers d'une population essentiellement préoccupée par la survie quotidienne. Le ministère de la Culture se démène comme il peut, tous ses ressorts sont tendus, mais il ne possède pas de baguette magique pour résoudre tous les problèmes de la société.

\section{Palais al-Sakâkînî : projet de musée de la médecine}

Manifestation éclatante du style rococo, le palais al- Sakâkînî est situé sur la place du même nom, au cœur du quartier alZâhir au Caire. Il a été construit en 1315/1897 par des architectes italiens pour le compte de Habîb pacha b. Gibrâ'îl b. Antûn b. Ilyâs b. Hannâ Sakâkînî. Cette famille chrétienne d'origine syrolibanaise a émigré en Égypte au cours de la première moitié du XIX ${ }^{e}$ siècle pour fuir les persécutions ottomanes. Habîb pacha Sakâkînî (m. 1923) fut I'une des grandes figures de l'aristocratie égyptienne du XIXe siècle. II participera au creusement du canal de Suez. Son succès fulgurant dans l'immobilier et les travaux publics incitera le khédive 5. Palais al-Sakâkînî

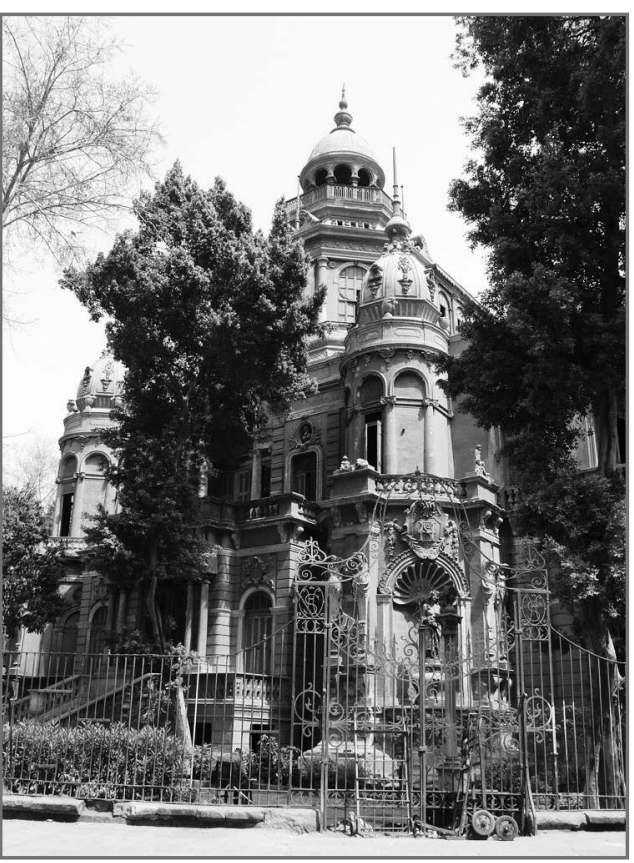
Ismâcîl à lui confier la construction de l'Opéra du Caire en 1869. Le palais al-Sakâkînî de 2698 m² $^{2}$ se compose d'un sous-sol, de trois étages, d'un ascenseur, de quatre tours et d'un vaste jardin agrémenté de bassins, de fontaines en marbre et de diverses sculptures. Le rez-de-chaussée abrite un grand hall de réception et le bureau du pacha dont le portrait est toujours gravé sur le plafond. Le deuxième étage était occupé par la famille, alors que l'ensemble des domestiques occupait le dernier étage.

Dans les années 1960, I'un des petits-fils de Sakâkînî qui était médecin concède sa part d'héritage au ministère de la Santé pour que le palais soit transformé en musée de la médecine. Le reste de la famille fait de même - nationalisation oblige. Mais, faute de moyens et de savoir faire, le ministère de la Santé ne parvient pas à concrétiser ce projet durant trente années de tutelle. En 1997, ce palais centenaire fut inscrit sur l'inventaire des monuments islamiques, conformément à la loi 117/1983. En août 2003, le CSA charge une commission de spécialistes d'élaborer un projet de restauration et de documentation du palais tombé en décrépitude. Une fois réhabilité, les ministères 
de la Santé et de la Culture envisagent sa transformation en un musée retraçant l'histoire de l'évolution de la médecine depuis l'époque pharaonique jusqu'à l'âge d'or des sciences arabes. Ce musée est destiné à exposer les récentes découvertes archéologiques comme les instruments chirurgicaux découverts dans la région d'Abydos, en plus des papyrus médicaux trouvés sur d'autres sites ou prêtés par le Musée copte et celui d'Art islamique. Un pavillon sera consacré aux techniques de la momification. Depuis 2003 et mis à part quelques gesticulations médiatiques par-ci par-là, rien de palpable n'a été entrepris dans ce palais dont l'état ne cesse de se dégrader. Le rez-de-chaussée est aujourd'hui occupé par les fonctionnaires de l'inspectorat du centre du Caire, qui en interdisent la visite. Soulignons, enfin, que plusieurs scènes du film L'immeuble Yacoubian ont été tournées dans ce palais avec, bien sûr, l'autorisation du CSA. La séquence finale regroupe près de trois mille acteurs et figurants rassemblés devant l'entrée délabrée et les grilles rouillées du palais. Espérons que la somme rondelette qu'a dû rapporter ce tournage aidera le CSA à hâter son intervention. Même si le choix d'un tel palais pour abriter un musée de la médecine reste pour le moins curieux.

\section{Palais du prince Sacîd Halîm : projet de musée de I'histoire du Caire}

Obsédé par la ville de Rome où, ironie du sort, il sera assassiné par un agent américain le 6 décembre 1921, le prince Sacîd Halîm, grand vizir de l'empire ottoman et petit-fils de Muhammad 'Alî Pacha, confie en 1896 au célèbre architecte austro-italien Antonio Lasciac la construction de ce palais de deux étages avec des matériaux importés spécialement d'Italie. Situé rue Champollion en plein centreville du Caire, ce palais sera confisqué par les Anglais à la veille de la Première Guerre mondiale en raison de l'engagement de son châtelain en faveur des Ottomans. Ensuite, il sera loué au ministère de l'Éducation et transformé en école préparatoire al-Nâsiriyya entre 1934 et 2004. En 2000, ce grand édifice d'une superficie de $1600 \mathrm{~m}^{2}$ sera vendu par ses héritiers à une société immobilière (El Fath for Real Estate Investments), qui planifie la construction de buildings dans son vaste jardin. Pour contrecarrer ce projet spéculatif, le palais est classé sur la liste du patrimoine par décret $n^{\circ} 121 / 2002$. En vertu de la loi 117/1983, ses nouveaux acquéreurs peuvent l'occuper, voire le revendre, mais en aucun cas y entreprendre des modifications de quelque nature que ce soit sans l'aval et la supervision du CSA. Il faut attendre mai 2006 pour que - au terme d'un long conflit - le ministère de l'Éducation se résolve à évacuer l'école al-Nâsiriyya et à céder au ministère de la Culture la tutelle de ce palais auquel le manque de soins et de maintenance au cours des deux dernières décennies a infligé de nombreux stigmates.

Début 2005, le CSA approuve une proposition émise par I'urbaniste Galila El Kadi, directrice de recherche à l'Institut de recherche pour le développement (IRD), et le bureau de consultation égypto-français MIMAR Engineering 
Consultancy SAE, visant à la réhabilitation et à la transformation de ce palais en musée historique du patrimoine du Caire. Ce projet s'inscrit dans le cadre d'un programme de partenariat euro-méditerranéen qui cherche à préserver le patrimoine architectural datant de la fin du XIX et du début du XXe siècles au Caire et à Alep. L'IRD s'occupera de la coordination $d^{\prime}$ une équipe de recherche regroupant I'Institut universitaire d'architecture de Venise (Università luav di Venezia) et les facultés de polytechnique du Caire et d'Alep. À l'instar du musée Carnavalet qui abrite la mémoire de Paris, le musée envisagé retracera l'histoire du

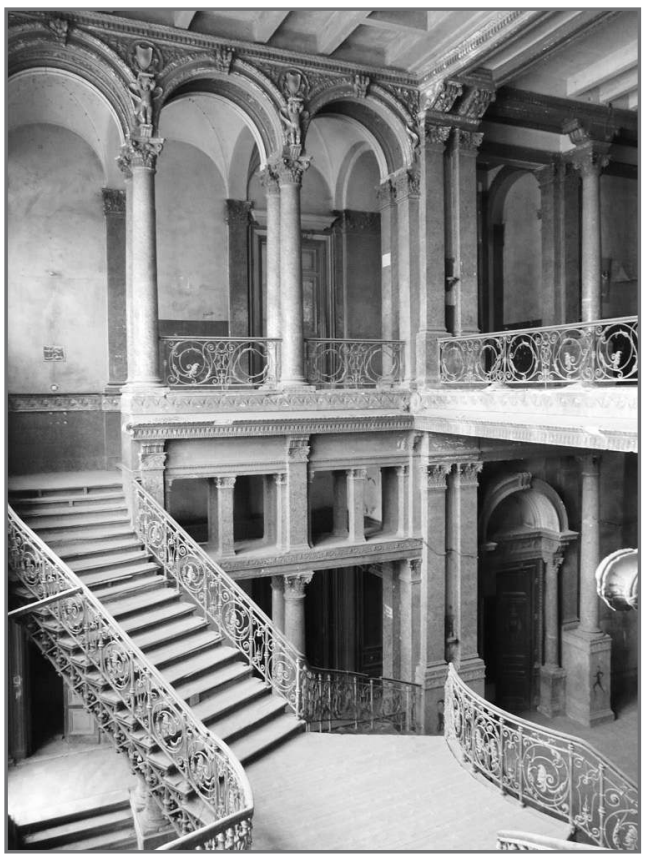

6. Palais du prince Sacîd Halîm Caire, des origines à nos jours, des points de vue économique, social et urbanistique. Il restituera les événements majeurs qui s'y sont succédé et les personnalités qui y ont joué un rôle crucial. Des cartes de la ville de différentes époques y seront exposées, ainsi que les vêtements, les parures, les monnaies, le mobilier et les moyens de transport qu'a connus cette mégapole. Une section sera dédiée à l'histoire d'avant Le Caire telle qu'elle se reflète à travers les découvertes archéologiques. Le musée exposera des maquettes des métiers et des artisanats traditionnels et des lithographies du peintre écossais David Roberts. Une bibliothèque reliée à Dâr al-Kutub, aux différentes universités et centres de recherche facilitera l'accès aux informations sur l'histoire de la ville. Le musée comprendra également un volet culturel et de divertissement destiné aux jeunes, ainsi qu'une librairie, des salles de conférences et de projection de documentaires tirés des archives cinématographiques retraçant l'évolution de la ville.

Toutes ces activités seront financées par la vente de souvenirs, de moulages, de CD-Rom et autres produits dérivés. Le coût de création de ce musée est estimé approximativement à 20 millions de livres égyptiennes, somme qui pourrait être financée par le mécénat et les centres de recherche installés en Égypte. Dans le cadre du programme Hercomanes, I'Union européenne assurera le financement de l'étude, des relevés architecturaux et de I'avantprojet. Quant aux travaux de restauration, ils seront à la charge du CSA. Des contacts ont été établis avec quelques anciens élèves de l'école al-Nâsiriyya, afin de créer une association des amis du musée chargée du sponsoring et de 
la quête des dons nécessaires. Enfin, soulignons que ce projet de réaffectation n'est pour l'instant qu'un vœu pieux qui, pour être exaucé, doit surmonter un champ d'écueils. À commencer d'abord par le rachat du palais à la société immobilière privée, qui risque d'exiger des sommes faramineuses. Interpellé devant le Parlement en juin 2006, le Dr Zâhî Hawwâs, reconnaît que :

"Le CSA a engagé depuis février dernier une procédure d'acquisition du palais. Procédure qui est loin d'être facile et qui demandera pas moins de trois ans avant d'aboutir !».13

En attendant, des gardiens et des inspecteurs du CSA montent vaillamment la garde.

Toutefois, la presse cairote continue à publier des éléments troublants sur ce dossier. En septembre 2006, l'organe du ministère de la Culture annonce qu'un comité d'inspection du palais Sa'îd Halîm a rejeté la proposition de le transformer en un musée de l'histoire du Caire. Néanmoins, une procédure d'expropriation est en cours afin de protéger cet édifice. ${ }^{14}$ À peine un mois plus tard, la presse fait état d'un accord conclu entre le CSA et l'Aga Khan Trust for Culture (AKTC) en vue de la construction du Cairo's First City Museum. La pointe Nord du parc al-Azhar a été choisie pour l'implantation de ce musée, qui s'adresse à un spectre large de visiteurs. Celui-ci retracera l'histoire de la ville du Caire et son évolution depuis l'époque pharaonique jusqu'à nos jours.

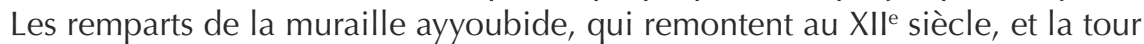
seront intégrés dans le scénario muséologique. Des écrans géants permettront d'exposer l'histoire du Caire avec, à l'appui, des cartes et un récit narratif dans différentes langues extrait des descriptions laissées par différents voyageurs et

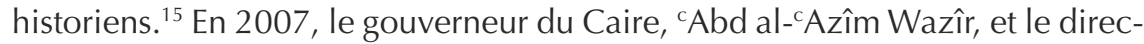
teur général de I'AKTC, Luis Monreal, posent effectivement la première pierre du projet de création d'un complexe culturel et commercial et du premier parking souterrain dans le quartier d'al-Darrâsa. M. Wazîr annonce que le coût de ce projet implanté sur une superficie de $4800 \mathrm{~m}^{2}$ s'élève à 163 millions de livres égyptiennes. II se compose de quatre étages, d'un garage d'une capacité de 630 places, d'un centre commercial et d'un musée qui retrace l'histoire de la ville du Caire. ${ }^{16}$ Le Cairo's First City Museum n'est-il pas un doublon du projet de musée de l'histoire du Caire ? Le CSA a-t-il abandonné définitivement le projet de réaffectation du palais Sacîd Halîm ? Et si oui, pourquoi il ne I'annonce pas franchement? Pour l'instant, toutes ces questions baignent dans un flou artistique.

13. Akhbâr al-Adab, 18 juin 2006.

14. Al-Qâhira, 12 septembre 2006.

15. Al-Qâhira, 7 novembre, Al-Ahram Hebdo, 8 novembre 2006.

16. Al-Ahrâr, 21 juillet 2007, Al-Ahrâm, 25 juillet, Daily News Egypt, 16 août, Al-Wafd, 17 août, Akhbâr al-Yawm, 24 novembre, Al-Ahrâm, 24 janvier 2008. 
Palais Muhammad bey al-Shinnâwî : projet de musée archéologique de Daqahliyya

Construit en 1930, ce palais de $700 \mathrm{~m}^{2}$ situé rue al-Gumhûriyya sur la corniche de Mansûra a été la résidence de Muhammad bey al-Shinnâwî, l'un des leaders du parti libéral al-Wafd. Il a joué un rôle important dans le mouvement nationaliste au cours de la première moitié du $X X^{\mathrm{e}}$ siècle. Le palais se compose d'un soussol et de deux étages entourés $\mathrm{d}^{\prime}$ un vaste jardin. Inscrit sur l'inventaire des monuments historiques par décret du Premier ministre $\mathrm{n}^{\circ} 1548$ du 8 mai 1999, le CSA décide de transformer ce bâtiment de style architectural italien, caractéristique de la fin du XIXe et du début du $X X^{e}$ siècles, en un musée pour exposer les milliers de pièces archéologiques entreposées non seulement à Daqahliyya, mais aussi dans les magasins de Tell

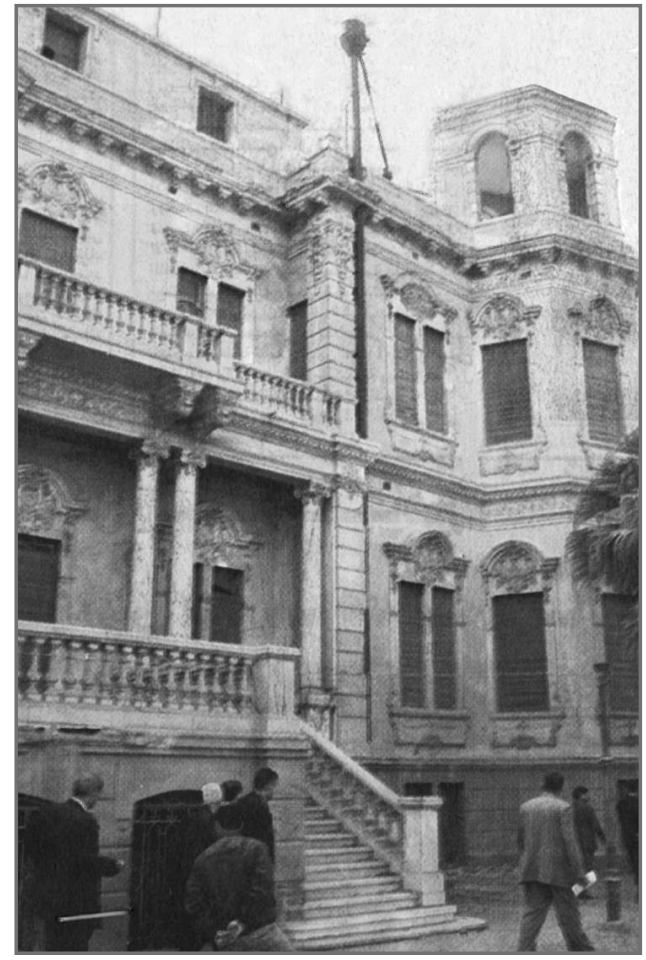

7. Palais Muhammad bey al-Shinnâwî.

Bastâ et de Damiette. Toutefois, ce projet ne fait pas I'unanimité parmi les experts. Contrairement à l'ex-directeur général des antiquités de Daqahliyya, Ahmad al-Surûgî, le chef du département d'archéologie de la faculté de lettres de Mansûra, Dr ${ }^{\mathrm{C}}$ Abdallah ${ }^{\mathrm{c}}$ Atiyya, juge ce palais inapproprié pour un tel projet. De même, Ridâ Sayyid Ahmad, professeur d'égyptologie à la faculté de lettres de Mansûra, estime que vu la somme colossale de 16 millions de livres égyptiennes investie dans l'acquisition de ce palais, le CSA aurait pu choisir un autre emplacement plus adéquat. ${ }^{17}$

Bien sûr, il est assez tentant de faire $d^{\prime}$ une pierre deux coups : restaurer un bâtiment d'une grande valeur historique ou architecturale et, en même temps, en faire un musée régional. Mais ce postulat ne devrait pas être systématiquement appliqué. Cette politique doit être examinée au cas par cas, dans la mesure où chaque bâtiment est unique en quelque sorte. Car malgré le succès indéniable de la transformation du palais Fâtima Haydar en musée des Bijoux 
royaux, ou celui de $A s^{c}$ ad pacha Bâsîlî en musée national d'Alexandrie, force est de reconnaître qu'il n'en va pas de même pour le palais Muhammad bey al-Shinnâwî, dont les travaux de réaménagement n'ont toujours pas démarré au bout de presque huit années.

Pour mieux illustrer notre propos, citons un second exemple: le palais d'Alexan Abaskharoun situé à l'Est d'Asyût (cf. Fig. 7). Avocat de formation, chef de la communauté protestante, Alexan pacha était l'une des plus grosses fortunes d'Asyût et de Haute-Égypte. Fondé en 1910 sur une superficie de $7000 \mathrm{~m}^{2}$, ce palais se compose de deux étages, de quinze chambres et d'un vaste jardin. Des architectes italiens, français et britanniques avaient participé à l'édification de cet édifice qui, grâce à son style architectural particulier, fait partie des curiosités du gouvernorat d'Asyût. Abandonné suite au décès de son propriétaire, il a fallu attendre 1996 pour que ce palais soit inscrit sur la liste du patrimoine islamique par décret du Premier ministre $n^{\circ} 1931$. Le Comité permanent des antiquités égyptiennes du CSA approuve, en 2003, sa transformation en musée archéologique régional après avoir entrepris les restaurations architecturales nécessaires. ${ }^{18}$ En outre, la situation du palais Abaskharoun en bordure du fleuve, facilement accessible aux bateaux de croisière, est censée contribuer à l'essor du tourisme national. Aujourd'hui, cinq ans plus tard, ce projet n'a pas avancé d'un iota.

Il faudrait apprendre à mieux se méfier des relents de systématisation et à résister au chant des sirènes de la répétitivité. On ne saurait transformer toutes les demeures bourgeoises du Caire en centres culturels. Tout comme on ne saurait convertir tous les palais décatis de province en musées régionaux. Ça serait trop facile ! On le voit bien, cette politique de décentralisation muséale et de développement des collectivités territoriales - au demeurant louable - atteint vite ses limites. Car les musées du XXIe siècle sont des établissements technologiques d'une extraordinaire complexité. Rien à voir avec les musées d'antan ou les cabinets de curiosité de jadis : étalages poussiéreux, hétéroclites et désuets qui fleurent bon la nostalgie gentillette d'un temps à jamais révolu. Muséographie et muséologie sont des disciplines à part entière et font l'objet d'un enseignement scientifique. Laisser croire qu'il suffirait de quelques rafistolages pour transformer une vieille bâtisse en musée digne de ce nom serait à coup sûr une douce illusion.

\section{Palais al-Ablaq : projet de musée des portails du Caire historique}

Les portes et portails des monuments sont constamment soumis à rudes épreuves : pollution et rigueur climatiques, hausse du niveau des eaux souterraines, surélévation des chaussées, vol d'accessoires, utilisation abusive des habitants, etc. C'est pourquoi certains d'entre eux ont été démontés, rem-

18. Akhbâr al-Yawm, 15 novembre 2003, Uktubar, 9 avril 2006, Al-Wafd, 20 juillet 2007. 
placés par des répliques et conservés à l'abri. Le musée d'Art islamique, par exemple, abrite les portails des mosquées Barsbây, al-Azhar, al-Sâlih Talâ'i ou celui du mausolée de l'imâm al-Shâficî. The Arab Fund for Economic and Social Development (AFESD) contribue, à travers un don de 1 million de dollars, au projet de restauration et de transformation du palais al-Ablaq en un musée des portails du Caire historique. Ce palais, d'époque mamelouke, fondé par le sultan al-Nâsir Muhammad en 1314/1896, est situé au sud de la mosquée Muhammad 'Alî dans l'enceinte de la citadelle de Salâh al-Dîn al-Ayyûbî. Placé sous la direction du $\operatorname{Dr} \mathrm{As}^{\mathrm{c}}$ ad Nadîm, ce projet consiste en sa transformation en un lieu d'exposition des portes, portails, matériaux, accessoires (poignées, heurtoirs, cales, etc.) et techniques de leur fabrication. En plus d'un laboratoire de restauration et de maintenance. Le ministère de I'Agriculture a prêté son concours pour débarrasser le palais des chauves-souris et autres reptiles qui l'envahissaient. Une base de données informatique sera installée pour fournir des informations scientifiques aux spécialistes et visiteurs. Un inventaire sera dressé de ces portails, de leurs emplacements, soit in situ, soit dans des musées ou des entrepôts, une documentation photographique et historique des portails. Ces données visent également à enrichir les différents artisanats de bois et de métaux et à rehausser le niveau des artisans traditionnels. En mars 2003, le Dr Nadîm prévoyait I'achèvement des travaux dans quatorze mois. Aujourd'hui, ce projet intéressant semble piétiner.

\section{DEMEURES BOURGEOISES}

\section{Bayt al-Sitt Wasîla}

Située à une centaine de mètres au sud de la mosquée al-Azhar, au cœur du Caire islamique, cette magnifique maison (bayt plur. buyût) a été fondée en 1074/1663 par un certain 'Abd al-Haqq al-Kinânî et son frère Lutfî. Comme la majorité des demeures bourgeoises, elle passe entre plusieurs mains. Elle porte le nom d'une illustre inconnue, al-Sitt Wasîla Khâttûn, la dernière maîtresse de céans qui y a résidé en 1836. Un escalier de six marches mène au rez-dechaussée, qui se trouve aujourd'hui en contrebas du niveau de la voie. On y trouve une vaste salle réservée à la réception et aux réunions des hommes. Le premier étage abrite le gynécée décoré de belles boiseries et surmonté d'un splendide plafond à solives apparentes. À ses heures de gloire, Bayt al-Sitt Wasîla fut l'une des maisons les plus impressionnantes de l'époque ottomane. Mais, avec le temps, elle s'est considérablement délabrée, notamment après le séisme de 1992. Murs attaqués par la hausse du niveau des eaux souterraines, I'humidité et les remontées de sels, façades craquelées, éléments décoratifs et architecturaux perdus (portes, fenêtres, plafonds, sols, fontaine en marbre) : l'état de cette maison n'a cessé de se dégrader jusqu'en 2002, lorsqu'elle fut inscrite sur la liste des monuments à préserver dans le cadre du projet de réhabilitation du Caire historique. 
Lors des travaux de restauration effectués par une équipe du CSA, une grande peinture murale $(3 \times 2,5 \mathrm{~m})$ a été découverte dans le maqcad al-sayfî (salle de résidence d'été) au premier étage de la maison montrant l'entrée d'une ville fortifiée. Le nettoyage des murs de l'édifice a révélé la présence de près d'une vingtaine $d^{\prime}$ autres magnifiques fresques dont la plus

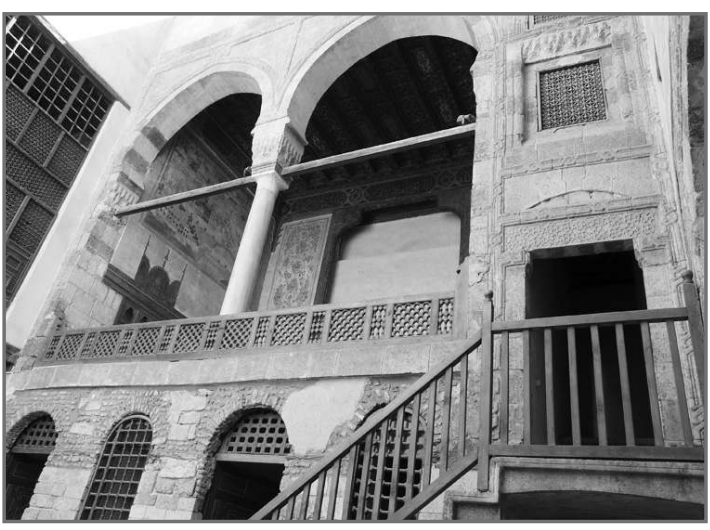

8. Bayt al-Sitt Wasîla impressionnante dépeint un pèlerinage à la $K a^{c} b a$. La plupart de ces peintures sont en bon état de conservation et gardent encore leurs couleurs vives. C'est bien la première fois qu'un aussi grand nombre de fresques islamiques est mis au jour dans une résidence privée de cette époque. Dans les années 1980, I'architecte Bernard Maury y avait déjà sauvé quatorze fresques. Restaurées et entreposées dans les magasins du CSA à la Citadelle du Caire, celles-ci ont réintégré récemment leur emplacement d'origine dans la maison.

À l'issue de quatre années de travaux de restauration dont le coût s'élève à 5 millions de livres égyptiennes, Bayt al-Sitt Wasîla est inaugurée le 3 juillet 2005 par le Premier ministre, Ahmad Nazîf, le ministre du Tourisme, Ahmad al-Maghrabî, le gouverneur du Caire, ${ }^{c} A b d$ al-cAzîm Wazîr et le secrétaire général du CSA. Le ministère de la Culture décide de transformer cette maison en un centre de rayonnement culturel, à l'instar des demeures voisines d'alHarrâwî, de Zaynab Khâttûn ou d'al-Suhaymî. Concerts de musique, congrès, réceptions de chefs d'État, dîners de délégations étrangères, représentations théâtrales, chants sacrés, profanes ou folkloriques, spectacles de marionnettes ou de contes, soirées poétiques, expositions de peinture ou de photographies : les activités pratiquées dans ces demeures se déclinent sur une palette très riche. Elles attirent un large public toute l'année et, surtout, durant les nuits du ramadân. Les spectacles gratuits se déroulent dans la mesure du possible dans le jardin ou la cour intérieure du monument. Les inspecteurs du CSA et le personnel du Fonds de développement culturel veillent au bon déroulement de ces soirées. Ils s'appuient sur un règlement intérieur qui définit la discipline à observer et proscrit notamment de : fumer, cuisiner, faire du feu, introduire du charbon ou des bonbonnes de gaz, salir ou toucher le monument, planter des clous dans les murs, installer un décor ou des équipements lourds, générer de fortes vibrations sonores, etc. En toute objectivité, on peut dire aujourd'hui que I'expérience a pleinement réussi, même si beaucoup de progrès restent encore à faire : assurer une meilleure publicité pour ces spectacles, en faire respecter les horaires, améliorer le confort des spectateurs assis sur des chaises incom- 
modes, créer des aires de stationnement, décentraliser ces activités concentrées dans la seule ville du Caire... Aujourd'hui, Bayt al-Sitt Wasîla est ouverte au public, mais son projet de réaffectation culturelle est resté lettre morte.

\section{Bayt Ibrâhîm al-Sinnârî}

C'est en 1209/1794 que Ibrâhîm Katkhudâ al-Sinnârî a construit cette demeure de 1000 $\mathrm{m}^{2}$ située dans la ruelle Monge à Sayyida Zaynab. Originaire de Dongola au Soudan, al-Sinnârî débarque en Égypte à un jeune âge, apprend le turc et gravit très vite les échelons sociaux pour faire partie des notables de la cité sous le règne de Murâd bey, l'un des deux principaux maîtres

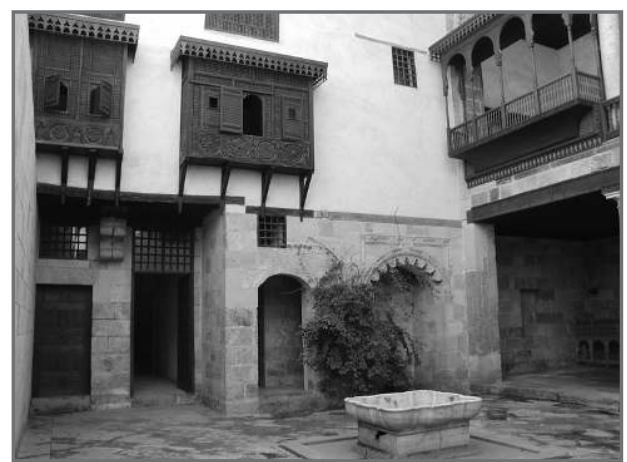

9. Bayt Ibrâhîm al-Sinnârî (Bernard Maury). du pays. Cette maison ${ }^{19}$ d'époque ottomane présente plusieurs caractéristiques des demeures du XVIII e siècle : façades simples surmontées de mashrabiyya (fenêtres grillagées en bois tourné), qâca (grande salle), maqcad pour recevoir les invités et takhtabûsh (portique intérieur) qui donnent sur une cour décorée d'une belle vasque en marbre. Mais son importance réelle provient du fait qu'elle fut réquisitionnée par Bonaparte à la suite de l'entrée victorieuse des Français au Caire. Entre 1798 et 1801, elle sert de résidence aux savants de l'Institut français. En 1951, le CSA inscrit cette maison sur la liste du patrimoine et en confie les travaux de restauration à l'architecte français Bernard Maury à partir de 1996. Il a fallu six ans et 4 millions de livres égyptiennes pour mener à bien ce lourd projet. Pour résoudre définitivement le problème de la hausse du niveau des eaux souterraines qui menaçaient sérieusement la maison, les travaux se sont élargis pour englober I'installation de nouveaux réseaux d'eau, d'égout et d'électricité.

En novembre 2004, Bayt al-Sinnârî est à nouveau ouverte à la visite. Le Comité permanent du CSA approuve la réutilisation de certaines pièces en bibliothèque et centre culturel. La cour à ciel ouvert et le jardin sont dédiés à la célébration d'activités artistiques et musicales. Toutefois, cette maison peine toujours à se redécouvrir une véritable vocation. Une impression mélancolique d'inachevé se dégage de ses murs, malgré deux projets intéressants de réaffectation qui sont tombés à l'eau. Le premier consistait, tout naturellement,

19. Nous remercions vivement Bernard Maury pour sa coopération et ce cliché de Bayt al-Sinnârî montrant la cour intérieure avec vasque et mashrabiyya, qu'il a bien voulu mettre à notre disposition. 
à transformer Bayt al-Sinnârî - que les habitants de Sayyida Zaynab continuent à appeler Bayt Napoléon - en un musée Bonaparte. Deux obstacles insurmontables : l'impossibilité de réunir une collection et l'opposition farouche des nationalistes égyptiens pour qui la Campagne d'Égypte reste avant tout une invasion militaire détestable. Même si les troupes napoléoniennes avaient entraîné dans leur sillage géographes, architectes, botanistes, ingénieurs et autres artistes de la fameuse Description de l'Égypte. La seconde idée proposée par Bernard Maury était d'y créer une école de la pierre où compagnons du tour de France et tailleurs de pierre égyptiens peuvent se rencontrer et échanger leur savoir-faire. Bien entendu, rien n'empêche de concrétiser cette seconde idée dans un autre monument.

\section{Bayt al-Umma (maison de la nation)}

Cette demeure bâtie aux environs de 1901, située à Lâzughlî dans le quartier de Munîra, a été occupée par le leader nationaliste Sacd Zaghlûl jusqu'à sa mort le 23 août 1927. Elle fut le siège de la révolution de 1919 et témoin des événements politiques, réunions et sursauts populaires majeurs contre le protectorat britannique. C'est son épouse Safiyya Zaghlûl, surnommée Umm al-masriyyîn (la mère 10. Bayt al-Umma

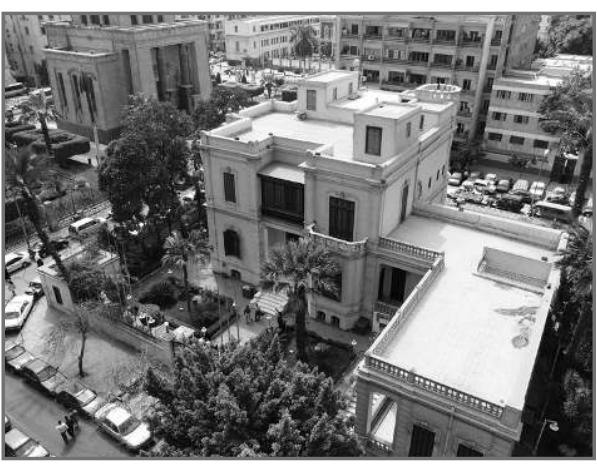
des Égyptiens), qui a demandé de transformer la maison après sa mort (janvier 1964) en un musée de la Nation, qui reflète l'émergence et l'évolution du nationalisme égyptien au lendemain de la première guerre mondiale. Le premier étage renferme une salle de réception pour les différentes délégations, une salle à manger avec une grande table servant pour les réunions et le bureau de $\mathrm{Sa}^{\mathrm{c}} \mathrm{d}$ Zaghlûl dont les murs sont décorés de plusieurs photographies et documents dont un certificat d'appartenance à la Grande Loge de France. Le second étage abrite les appartements privés.

Lancées en 1998, les restaurations de cette demeure ont coûté environ 5 millions de livres égyptiennes et ont duré quatre ans. Un travail qui s'est déroulé en deux étapes principales. Tout d'abord la conservation de l'édifice, mélange d'architecture classique, arabe et art nouveau. Ensuite, la restauration du mobilier, l'aménagement des vitrines d'exposition, l'installation de systèmes de sécurité, de surveillance, de climatisation, $d^{\prime}$ un nouveau réseau de drain sanitaire et le réaménagement du jardin $\left(2500 \mathrm{~m}^{2}\right)$. Ce projet a été entravé, notamment, par la difficulté architecturale de convertir une demeure ordinaire de $596 \mathrm{~m}^{2}$ en un musée. Mais il a également permis de découvrir les copies originales des mandats donnés par le peuple égyptien à $S a^{c} d$ Zaghlûl 
pour négocier, à Londres, I'indépendance de l'Égypte durant la Première Guerre mondiale. Ces documents exceptionnels sont à présent exposés pour la première fois dans les vitrines. On y trouve également deux cent trentehuit pièces de mobilier, trente-quatre tapis, six manuscrits, seize décorations, des sculptures de différentes tailles, treize peintures, soixante-quinze photos du fondateur du parti al-Wafd, de sa famille et de ses compagnons d'exil, ainsi que ses effets personnels (bureau, stylos, habits, cadeaux reçus, etc.). La fondation al-Ahrâm a contribué à la conservation de la bibliothèque, qui rassemble plus de trois mille ouvrages et périodiques dans différents domaines, en plus d'un exemplaire original de la Description de l'Égypte. Une salle de conférences d'une capacité de cent places et une salle d'exposition ont été aménagées dans le sous-sol de Bayt al-Umma. Celle-ci a été inaugurée par $M^{\text {me }}$ Suzanne Moubarak le 16 janvier 2003, accompagnée des ministres des Affaires étrangères et de la Culture, de nombreux intellectuels et, naturellement, du président du parti libéral al-Wafd, Dr Numân Gumª. Bayt al-Umma reçoit aujourd'hui de nombreux visiteurs, notamment des groupes scolaires.

\section{FONTAINES PUBLIQUES}

\section{Sabîl Muhammad 'cAlî : musée des Textiles islamiques}

La restauration de la fontaine publique (sabîl plur. asbila) de Muhammad 'Alî s'est achevée sur une question lancinante : que peut-on faire à présent de ce beau monument situé à al-Nahhâsîn dans le quartier d'al-Gamâliyya ? Personne ne semblait en avoir une idée claire et précise. Néanmoins, une chose est sûre : le fermer ou l'affecter aux bureaux administratifs du CSA risquerait fort de l'endommager à nouveau. Au même moment et comme par enchantement, la Bibliothèque nationale (Dâr al-Kutub wa-l-wathâ'iq al-qawmiyya) saisit le ministère de la Culture pour évacuer la salle des textiles située dans le musée d'Art islamique. Le hasard a donc joué un rôle déterminant dans la genèse du musée des Textiles islamiques. Épaulé, bien sûr, par les 12 millions de livres égyptiennes injectées par le CSA dans les travaux de transformation de ce sabîl fondé par Muhammad 'Alî, en 1244/1828, pour commémorer la mort au Soudan, six ans auparavant, de son fils, le prince Ismâcîl. Représentatif des asbila aménagés grâce à la générosité d'une personne pieuse, le Sabîl Muhammad 'Alî est réparti en trois niveaux. Une citerne souterraine où l'on stockait l'eau potable du Nil d'une façon saisonnière. Ensuite, un rez-dechaussée dont la façade principale nord-ouest donne directement sur la rue al-Mucizz. Cette façade semi-circulaire marbrée présente quatre fenêtres finement grillagées. La salle de plain-pied se compose d'une pièce rectangulaire pavée de marbre et couverte d'une coupole ovoïdale portant des décorations coloriées de styles baroque et rococo. Un escalier en pierre mène au premier étage, qui abritait jadis les logements du personnel et une école élémentaire de 
garçons (kuttâb). L'architecture des asbila, très répandus dans Le Caire islamique, offre de nombreux avantages. Leur structure qui aménage beaucoup d'espaces vides et leur superficie plus ou moins importante rendent leur réaffectation beaucoup plus aisée que les autres édifices. Ainsi que leur implantation au coeur des quartiers populaires qui manquent cruellement de services culturels et éducatifs.

La montée des eaux souterraines et l'existence $d^{\prime}$ une grosse citerne $(22 \times 12 \times 11 \mathrm{~m})$ à une profondeur de plus de onze mètres sous le bâtiment ont sérieusement retardé et compliqué les travaux de réfection.

Ceci a nécessité l'interven- 11. Sabîl Muhammad 'Alî

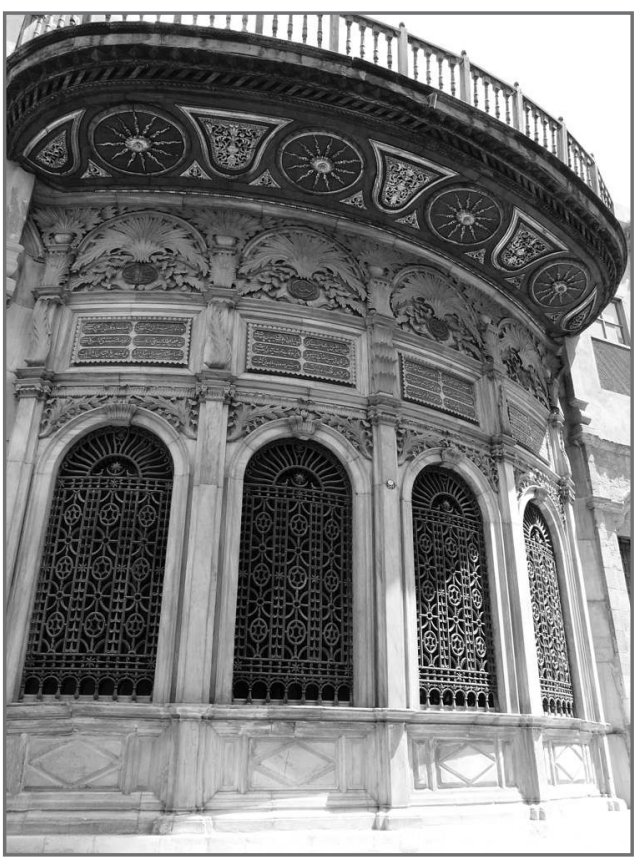
tion de plongeurs professionnels durant deux mois et le pompage progressif des eaux qui affectaient gravement les fondations. La collection du musée (deux cent cinquante pièces de textile et quinze tapis) provient du musée d'Art islamique et des différents entrepôts du CSA. Nettoyées et restaurées avec le plus grand soin, ces pièces datent, pour la plupart, de la période fatimide. Elles témoignent de la maîtrise technique exceptionnelle et du raffinement auxquels étaient parvenus les plus célèbres ateliers de tissage du monde islamique entre les $\mathrm{VII}^{\mathrm{e}}$ et $\mathrm{XV}$ e siècles. Plusieurs panneaux retracent I'histoire de l'industrie du textile précieux, des soieries, de la broderie, des métiers à tisser, des colorants et des outils. Ce musée qui se veut pédagogique et évolutif à la fois est placé sous la direction de Muhammad 'Abbâs qui, justement, prépare une thèse de doctorat sur les textiles islamiques.

Alors que le musée est sur le point d'être inauguré prochainement par le président Moubarak, une nouvelle idée surgit subitement dans la tête du ministre de la Culture : élargir ce musée à toute I'histoire des textiles en Égypte, depuis la période pharaonique jusqu'aux temps modernes. Du coup, I'appellation même du musée devra changer pour devenir le musée des Textiles égyptiens. Pour plusieurs spécialistes, cette idée a peu d'intérêt, d'autant plus que la superficie assez limitée du musée ne saurait abriter les textiles de toutes les époques. L'ex-président du Secteur des antiquités islamiques et coptes du CSA, Dr 'Abdallah Kâmil, critique cette réaffectation abusive des monuments restaurés à des fins antinomiques à leurs fonctions d'origine et peu respec- 
tueuse de leur environnement naturel. "Sur quelle base peut-on choisir un sabîl islamique, situé au cour du Caire fatimide, pour y exposer des textiles d'époque pharaonique ou romaine? ${ }^{20}$, s'insurge Dr Kâmil. Quoi qu'il en soit, le rez-de-chaussée est dédié à l'époque pharaonique à travers, par exemple, des vêtements de Toutankhamon et des bandelettes en lin. Le premier étage est consacré aux époques copte (robes de moines) et islamique (dessus-de-lit brodés d'or et d'argent, cadeaux de mariage offerts par Muhammad 'Alî à sa sœur) à travers un classement chronologique qui culmine avec une magnifique kiswa (tenture) offerte à La Mecque par le roi Fu'âd.

Enfin, Dr Usâma al-Nahhâs, professeur d'architecture à la faculté de Polytechnique de Shubrâ et ex-Président de I'Administration centrale pour I'architecture des musées au sein du CSA, critique la réaffectation du Sabîl Muhammad ${ }^{\mathrm{C}}$ Alî comme musée des textiles. ${ }^{21}$ Architecturalement conçu pour collecter puis redistribuer l'eau potable aux habitants du Caire, ce monument - où l'on enregistre un taux élevé d'humidité - n'est pas adéquat à la conservation ni à l'exposition des textiles qui, eux, nécessitent un milieu sec. Al-Nahhâs souligne que I'humidité expose les textiles antiques à la dégradation et favorise la prolifération des bactéries et des micro-organismes. L'architecture du sabîl aménage de multiples ouvertures d'aération garantissant une bonne circulation de l'air à l'intérieur du monument. Ce qui élimine les odeurs putrides dues à la stagnation de l'eau servie fraîche aux passants. Pour al-Nahhâs, un musée des textiles doit être implanté dans un milieu sec, à moins d'enfermer les pièces exposées dans des vitrines hermétiques. C'est d'ailleurs ce qu'a fait le ministère de la Culture. Toutefois, le danger réside dans les tapis accrochés simplement aux murs, car difficiles à mettre en vitrine. Ces tapis antiques sont donc exposés à de nombreux facteurs de dégradation dus à la hausse du niveau d'humidité dans ce sabîl.

Sabîl-kuttâb Qâytbây : Centre Suzanne Moubarak pour la civilisation islamique

Situé à l'extrémité de la rue al-Salîba à proximité de la place de la Citadelle, ce sabîl-kuttâb a été fondé en 884/1479 par le sultan al-Ashraf Abû al-Nasr Qâytbây. La somptuosité de ses trois façades, de ses incrustations de marbre polychrome, de ses sculptures, en pierre et en bois, de feuillages et de motifs floraux géométriques et calligraphiques, colorés et dorés, en fait I'un des principaux chefs-d'œuvre des fontaines publiques en Égypte. C'est l'unique sabîl indépendant ou autonome, c'est-à-dire qui n'est pas attaché à un édifice religieux ou funéraire. Particulièrement affecté par le séisme de 1992, les travaux de restauration de ce bâtiment ont duré quatre années et ont coûté

20. Akhbâr al-Adab, 15 juillet 2007.

21. Al-Badîl, 8 mai 2008. 
environ 5 millions de livres égyptiennes financés par I'Agencia Española de Cooperación Internacional (AECI). Ce fleuron de l'architecture mamelouke a été officiellement inauguré le 4 décembre 2000 par le ministre de la Culture, Farûq Husnî, I'ex-secrétaire général du CSA, Dr Gâballah 'Alî Gâballah, et le gouverneur du Caire, 'Abd al-Rahîm Shihâta.

Au rez-de-chaussée, le Fonds de développement culturel a créé une école arabe de cinéma et de télévision. Placée sous la direction du Dr Muna al-Sabbân, professeur à I'Académie du Cinéma, cette école virtuelle retrace, à travers son site Internet [http://arabfilmtvschool.edu. eg/l, I'histoire du cinéma des vingt-deux pays arabes et fournit des informations sur les festivals, les studios et les différentes institutions d'études cinématographiques. Ce site est le premier en son genre, dans le monde arabe, à s'intéresser à l'art et à l'industrie cinématographiques et télévisuelles : écriture de scénarios, réalisation, décors, montage, etc. Une bibliothèque a été créée pour

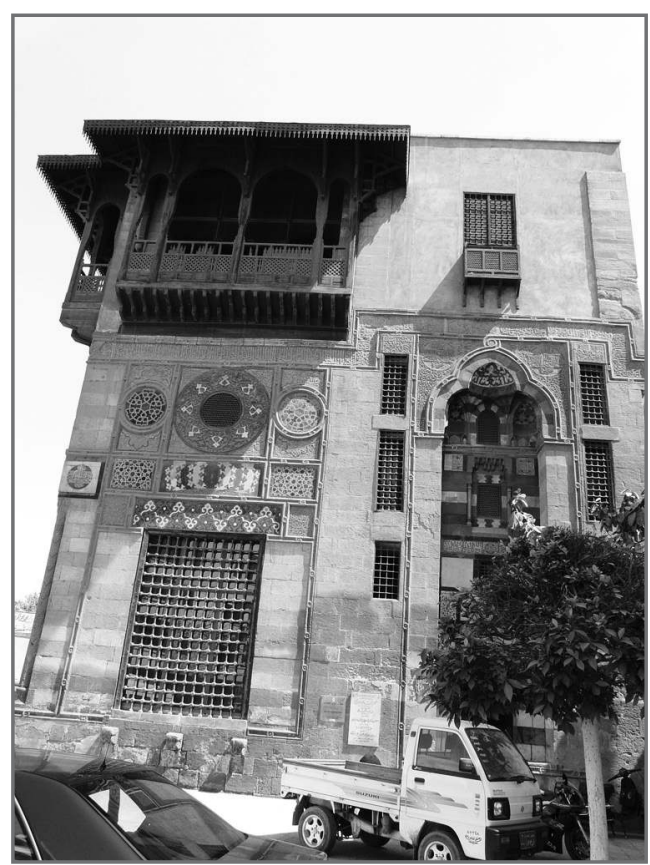

12. Sabîl-kuttâb Qâytbây abriter tous les ouvrages écrits ou traduits en arabe dans ce domaine et parus depuis 1920 jusqu'à aujourd'hui. Aider les chercheurs à retrouver facilement des références et les orienter à travers un fichier des sujets de magistère et de doctorat soutenus sur les arts et les techniques cinématographiques.

Le reste de ce bâtiment bien proportionné abrite la bibliothèque Suzanne Moubarak pour la civilisation islamique, une branche de la Grande Bibliothèque du Caire située à Zamâlik. Au premier étage a été aménagée une salle de conférences, une exposition de photos et de plans, quelques facsimilés d'anciens manuscrits, ainsi qu'une bibliothèque numérique moderne. Celle-ci permet aux chercheurs et aux étudiants en art et en architecture d'approfondir leur connaissance de la civilisation islamique à travers des bases de données, des enregistrements vidéo, des CD-Rom et des microfilms. Quant au second étage, il abrite une salle de lecture et plus de trois mille ouvrages dans différents domaines de la civilisation islamique : philosophie, religion, sciences sociales, art, architecture, littérature, histoire et géographie, en plus de nombreuses encyclopédies, périodiques, dictionnaires et atlas. La réutilisa- 
tion du Sabîl-kuttâb Qâytbây lui a ainsi donné une nouvelle vocation culturelle au service du district de Sayyida Zaynab. Et c'est dans ce sens-là qu'il peut être considéré comme un excellent cas d'école, même s'il n'est pas très fréquenté.

\section{CARAVANSÉRAILS}

\section{Wakâlat Bâzarca}

Le dimanche 18 mars 2001, $M^{\text {me }}$ Suzanne Moubarak inaugure officiellement Wakâlat Bâzarca, à l'issue de quatre années de restauration intensive, dont le coût s'élève à 4,8 millions de livres égyptiennes. Situé au 28 rue al-Tumbukshiyya, derrière la mosquée Gamâl alDîn al-Astâdâr dans le quartier d'al-Gamâliyya, ce caravansérail fondé au XVII ${ }^{e}$ siècle par l'émir Hasan Katkhudâ al-

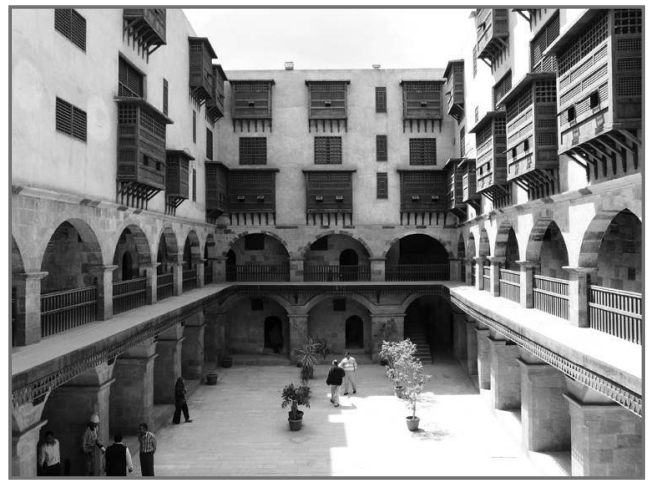

13. Wakâlat Bâzarca Kikhyâ, d'origine yéménite, était initialement connu sous le nom de Wakâlat al-Kikhyâ. On y pratiquait le commerce du bois jusqu'à la fin du XIXe siècle, lorsqu'il fut racheté par Muhammad Bâzarca. Ce riche négociant donna son nom au bâtiment qu'il consacra au commerce du savon de Syrie et du café du Yémen. La bourgeoisie des commerçants bâtira des fortunes colossales sur le commerce international des épices et du café, activité économique dominante de l'Égypte à partir de la fin du XVII e siècle. Comme tous les caravansérails, Wakâlat Bâzarca servait à I'hébergement des voyageurs de commerce et à la vente de leurs marchandises. Elle se compose d'un bâtiment quadrangulaire avec des galeries encadrant une grande cour centrale (sahn) de style mamlûk, bordée de magasins, d'écuries et d'entrepôts. Les chambres de différentes tailles, destinées à I'hôtellerie, se trouvent au premier étage, puis au second étage, réparties sur trois niveaux à mezzanines. Le président du Secteur des antiquités islamiques et coptes d'alors, Dr c Abdallah al-cAttâr, a orchestré les lourdes opérations de sauvetage de ce vaste bâtiment extrêmement dégradé : $800 \mathrm{~m}^{3}$ de gravats ont été retirés du chantier. Des fondations instables aux plafonds vermoulus, en passant par les escaliers effondrés, les portes et les fenêtres arrachées : tout a été consolidé, restauré ou remplacé. Un nouveau système d'éclairage et vingt-sept mashrabiyya-s en bois résineux ont été installés. Le projet du CSA a englobé l'installation d'un nouveau réseau de drain sanitaire et le réaménagement de toute la rue et des façades des maisons et des magasins avoisinants. 
En mars 2001, le ministre de la Culture, Farûq Husnî, annonce qu'il entreprend des contacts avec plusieurs pays (Turquie, Maroc, Iran, Inde, etc.), afin de transformer Wakâlat Bâzarca en une sorte de forum qui réunit les grands artisans. Ceux-ci peuvent y séjourner et créer des œuvres qui seront récompensées puis vendues lors d'un festival annuel. Wakâlat Bâzarca devrait également accueillir poètes, artistes et musiciens. ${ }^{22}$ Mais, en novembre 2002, Farûq Husnî abandonne cette idée de Centre international des arts et des artisanats. Il décide de transformer Bâzarca en ateliers de peinture et d'y transférer les artistes installés dans Wakâlat al-Ghûrî, qui doit subir des restaurations. ${ }^{23}$ Un comité composé du département des Arts plastiques et du Syndicat des artistes est chargé de l'attribution des trois cent studios individuels consacrés à la résidence des peintres et des sculpteurs dans Wakâlat Bâzarca. ${ }^{24}$ Cette bonne idée ne verra pas le jour non plus. Aujourd'hui, tout le rez-de-chaussée de ce caravansérail est affecté aux bureaux administratifs et d'inspectorats du CSA.

Rappelons que I'aménagement d'ateliers pour l'artisanat traditionnel et les arts plastiques dans Wakâlat al-Ghûrî remonte au début des années soixante, suite à une décision du ministre de la Culture de l'époque, Tharwat 'Ukâsha. Elle visait à procurer à une soixantaine de peintres ainsi qu'à une quarantaine d'artisans un cadre idéal pour stimuler leur imagination, tout en préservant le monument fraîchement restauré. Mais aujourd'hui, le ministère de la Culture tente d'apporter quelques ajustements au mode d'affectation d'ateliers aux artistes dans les monuments archéologiques : 1) Limiter la durée d'occupation des ateliers et assurer une meilleure rotation et une équité entre les utilisateurs, afin qu'ils puissent tous bénéficier du système à tour de rôle. En effet, les occupants actuels ont tendance à monopoliser les espaces durant des dizaines $d^{\prime}$ 'années. Certains d'entre eux s'expatrient tout en maintenant leurs ateliers fermés. D'autres pensent même pouvoir léguer leur atelier à leurs enfants ! 2) Interdiction totale d'apporter des modifications aux studios qui leur sont confiés, afin de ne pas nuire au monument. Certains artistes ont fait des branchements électriques sauvages qui auraient pu provoquer une catastrophe. 3) L'atelier devrait servir uniquement d'espace de travail et non de lieu d'habitat et d'hébergement. Pour les artistes, cette nouvelle réglementation sonne le glas de ce qui semble un prélude à la suppression des ateliers dans les bâtiments historiques. ${ }^{25}$ Un acquis farouchement défendu par les intéressés qui parlent d'un droit inaliénable et non d'une faveur du ministère de la Culture. De son côté, le ministre est persuadé de la nécessité de transférer les artisans installés au rez-de-chaussée, et dont les activités et les vibrations nuisent au

22. Al-Akhbâr, 16 mars 2001, Akhbâr al-Yawm, 17 mars 2001, Al-Ahrâm, 19 mars 2001, Âkhir Sâca, 21 mars 2001.

23. Al-Ahrâr, 18 novembre 2002.

24. Al-Ahrâm, 28 février 2003, Al-Ahram Weekly, 6 mars 2003.

25. Al-Qâhira, 18 et 25 mars 2003. 
monument, vers un nouveau centre de regroupement à Fustât, afin de préserver Wakâlat al-Ghûrî. Une polémique est née dans un climat de défiance entre le ministre et les artistes. Ceux-ci ont même intenté des procès contre le ministère de la Culture et le CSA devant le Tribunal administratif, et ont menacé de recourir aux ONG de défense des Droits de I'homme. Résultat de ce bras de fer : le ministre capitule, les artistes gardent leurs ateliers et 12 millions de livres égyptiennes sont affectés à la restauration du complexe funéraire et religieux d'al-Ghûrî (909/1504), dont 2 millions consacrés à la wakâla.

\section{ÉCOLES CORANIQUES}

\section{Madrasa al-cAynî}

L'école coranique (madrasa plur. madâris) al-cAynî, située rue al-Shaykh Muhammad 'Abduh derrière la mosquée al-Azhar, a été fondée en 814/1411 par Mahmûd b. Ahmad b. Mûsa b. Ahmad b. Husayn b. Yûsuf, alias al-cAynî. Né en 762/1360 à Gaziantep dans le Sud de la Turquie, ce célèbre shaykh débarque à la fin du XIVe siècle en Égypte. Sa connaissance de la langue turque lui assure une ascension fulgurante auprès des émirs et des sultans, notamment Farag b. Barqûq et al-Ashraf Barsbây. Il occupe et cumule plusieurs fonctions importantes au Caire et en Basse-Égypte dont celle de qâdî suprême des hana-

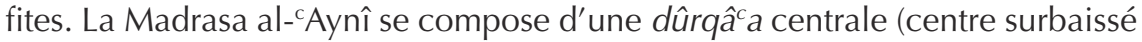
d'une grande salle) de forme rectangulaire communiquant avec deux iwân-s opposés sud-est et nord-ouest et d'un minaret. Elle servait à l'enseignement de I'islam sunnite à l'époque mamelouke. Un darîh (mausolée) de forme carrée a été ajouté dans l'angle Nord pour y enterrer al-cAynî, mort en 855/1451 après avoir laissé de nombreux ouvrages. Plusieurs années furent nécessaires pour restaurer ce bâtiment dans le cadre du projet de réhabilitation du Caire historique. Un centre de créativité artistique pour les enfants y a été aménagé par le Fonds de développement culturel avec le soutien du Club Inner Wheel, une des plus grandes organisations féminines de bénévolat et de service dans le monde. Le 6 juin 2003, ce centre de créativité entre en service et poursuit jusqu'à aujourd'hui plusieurs objectifs : 1) Favoriser l'esprit inventif des enfants, éveiller leurs talents artistiques et développer leurs connaissances. 2) Soutenir notamment les jeunes des quartiers al-Darb al-Ahmar et al-Ghûriyya dans le cadre des efforts déployés par de nombreuses associations et ONG dans ce secteur géographique. 3) Donner l'opportunité aux enfants d'exercer leurs talents et d'exposer leurs œuvres dans différents domaines : théâtre, musique, chorale, artisanats, etc.

L'évaluation de cette réaffectation nous plonge quelque peu dans l'embarras. Le projet est excellent, mis en place par un personnel jeune et dynamique et attire une myriade d'enfants non seulement du quartier, mais aussi des quatre coins du Caire. Le bâtiment n'est pas mal non plus. Pourtant il y a 
un couac d'ordre fonctionnel. Ce couac est dû tout simplement à I'inadéquation évidente entre les deux. En effet, le centre de créativité se répartit sur deux étages. Le premier abrite une cellule d'initiation à l'informatique - hors service pour l'instant - composée de deux pièces équipées de neuf ordinateurs. On y trouve également une pièce de jeux (puzzle, dessin, coloriage) en plus d'une pièce consacrée à l'inspecteur et au personnel du CSA. Le second étage comprend le bureau de la directrice, $M^{\text {me }}$ Amânî Mustafa, un magasin abritant des livres et une photocopieuse, une salle audiovisuelle pour la projection des dessins animés et des vidéos de culture générale, deux pièces de lecture pour les 6-8 ans et une autre salle de lecture pour les 8-13 ans. Toutes ces pièces sont trop étriquées pour accueillir confortablement la cinquantaine d'enfants qui fréquentent le centre, leurs tables, chaises et jeux. C'est pour

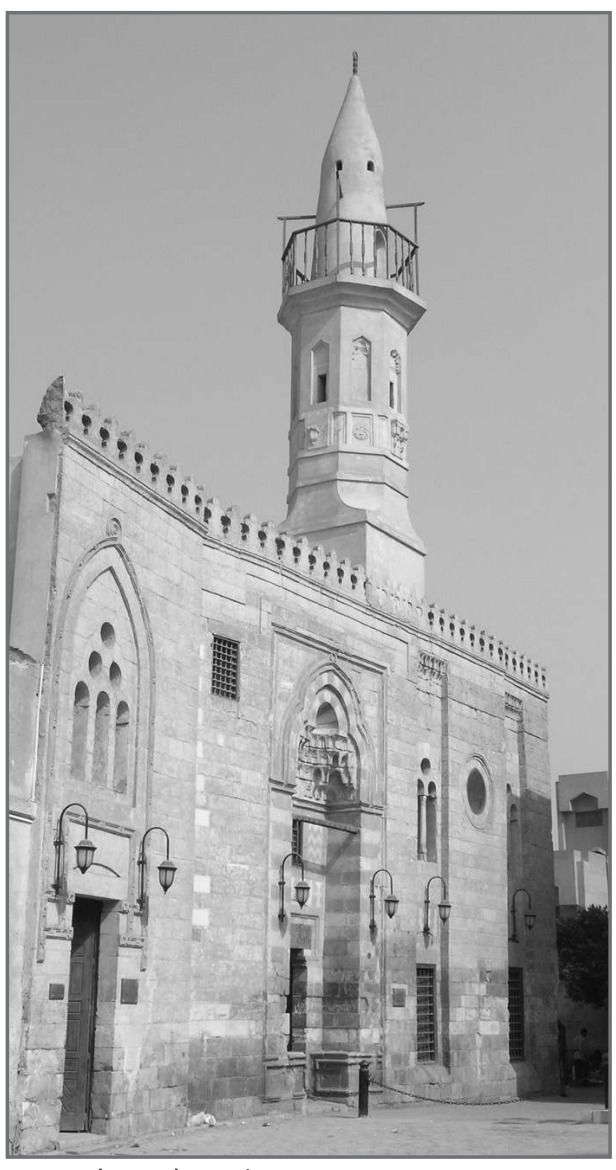

14. Madrasa al--'Aynî cette raison que les monitrices du centre se déplacent elles-mêmes et assurent des animations dans les écoles environnantes. Faute de place, les fêtes et les spectacles organisés par les enfants ont lieu sur la placette d'en face, dans Bayt al-Suhaymî et ailleurs. Dans ce bâtiment historique, il faut constamment veiller à ce que les enfants n'abîment pas les bas des murs, n'y clouent aucun dessin, etc. Dans des locaux ordinaires plus spacieux et susceptibles d'être facilement repeints, ces enfants pourraient s'amuser et apprendre plus commodément. Enfin, le centre de créativité est ouvert de $9 \mathrm{~h}$ à $16 \mathrm{~h}$ tous les jours, sauf le vendredi. Ces horaires administratifs ne respectent guère ceux des enfants qui ne peuvent s'y rendre qu'après l'école ou, a fortiori, le jour de congés.

Dans cet article, nous avons mentionné à plusieurs reprises le Fonds de développement culturel (FDC). Il est peut-être temps de rappeler qu'il a été créé en 1989 par décret présidentiel n 430 et placé sous la tutelle du ministre de la Culture. Depuis I'arrestation pour enrichissement personnel de Ayman 'Abd al-Muncim en août 2007, le FDC est dirigé par le Dr Ahmad Migâhid. Sa mission est titanesque : promotion de la culture, création de théâtres et de 
bibliothèques publiques sur tout le territoire, organisation de plusieurs festivals (cinéma, théâtre, sculpture), financement et gestion des activités culturelles organisées dans les monuments réaffectés. Avec plus de 50 millions de dollars, le FDC est un véritable trésor de guerre. Son budget provient de plusieurs affluents : un pourcentage prélevé sur les recettes du Conseil suprême de la culture (films, publications, publicités, musées), des dons et, surtout, $10 \%$ des recettes d'entrée des sites et des monuments historiques. Ce dernier détail constitue un brandon de discorde dans la mesure où archéologues et intellectuels refusent que l'argent du CSA soit affecté à d'autres enveloppes. Sur le terrain, les relations ne sont pas toujours au beau fixe entre le personnel du FDC et celui du CSA. Il y a pas mal d'interférences, de rivalité et de jalousie dues au fait que les premiers sont relativement mieux rémunérés et travaillent dans de meilleures conditions que les seconds. Les statuts et le cadre juridique du FDC sont beaucoup moins contraignants que ceux du CSA.

\section{CITERNES}

\section{Citerne Ibn al-Nabîh}

Dès l'époque ptolémaïque, plusieurs citernes (sihrîg plur. sahârîg) publiques ou privées, gigantesques ou plus modestes, ont été aménagées à l'échelle de la ville, afin d'emmagasiner l'eau potable et satisfaire les besoins des populations. Parfois, à la période musulmane, elles étaient surmontées de structures de type sabîl pour désaltérer les passants, ou de simples bassins pour abreuver les animaux. De l'Antiquité jusqu'au début du XXe siècle, les Alexandrins stockaient dans plusieurs centaines de citernes l'eau qu'un canal (khalîg) amenait depuis le Nil lors de sa crue en août-septembre, à une trentaine de kilomètres à l'Est de la ville. II suffisait, ensuite, de vivre sur ces réserves pendant le restant de I'année. Aujourd'hui, dans la ville d'Alexandrie, seules trois sont encore visitables : la citerne du fort de Qâytbây, celle d'Ibn Battûtah et celle d'Ibn al-Nabîh à Shallâlât. Située dans la rue Sultan Husayn, à I'angle Sud-est du jardin de Nubâr Pacha, cette dernière constitue I'un des témoignages précieux de l'infrastructure d'alimentation en eau de cette cité méditerranéenne. Totalement enterré, cet édifice d'une contenance d'environ $1000 \mathrm{~m}^{3}$ remonte à l'époque médiévale. Il est construit en partie grâce au remploi d'éléments architecturaux hétérogènes (colonnes, chapiteaux) provenant d'édifices antérieurs situés sur différents sites antiques. Ce vaste espace aux proportions harmonieuses se caractérise par un système de contreventement composé de quatre rangées de quarante-huit colonnes au total, entrecroisées d'arcs et réparties sur trois étages.

Avec I'introduction d'un réseau moderne de distribution d'eau courante au début du $X X^{\mathrm{e}}$, ces citernes tombent fatalement en désuétude. Classée monument historique dès 1900, ce n'est qu'en 1996 que le Centre d'études 
alexandrines (CEAlex) lance une étude scientifique de la citerne Ibn al-Nabîh ${ }^{26}$ à la demande du CSA. Campagnes de fouille croisées avec des études documentaires commencent alors à livrer des résultats prometteurs tant sur l'histoire de cet édifice d'une valeur architecturale indéniable, que sur le fonctionnement du régime de répartition de l'eau douce mis en place dans cette partie de la cité. En partenariat avec le groupe énergétique Gaz de France, le CEAlex élabore en 2004 un projet destiné à redonner vie à ce monument si caractéristique. Deux architectes DPLG, Laurent Borel et Chrystelle March, conçoivent le projet de conservation de cette 15. Citerne Ibn al-Nabîh (Laurent Borel).

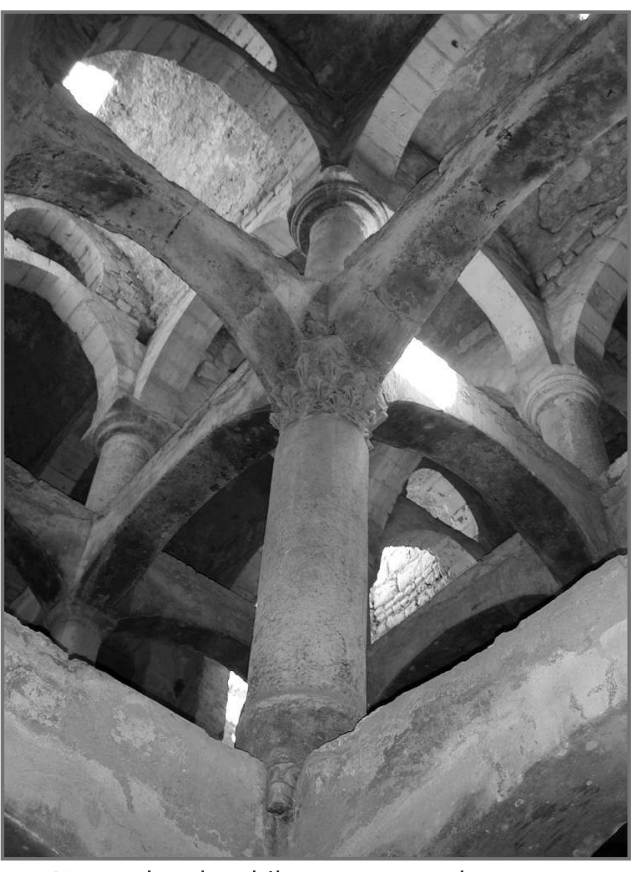
citerne et l'aménagement d'un musée sur I'hydraulique, illustrant à travers des maquettes de plusieurs autres réservoirs, comment les Alexandrins captaient, stockaient et redistribuaient I'eau durant plusieurs siècles. Des passerelles permettront aux visiteurs d'en explorer tous les étages. Un centre d'interprétation comprenant un espace d'exposition sera aménagé à proximité pour dispenser également des conférences à destination du grand public sur l'histoire des citernes d'Alexandrie et les différents dispositifs de remplissage et d'extraction des eaux de pluie ou de celles du Nil, des réservoirs. Un atelier éducatif et ludique sera créé où des animateurs apprendront aux enfants le façonnage des maquettes de citernes et la nécessité de préserver l'eau et les autres ressources de notre planète.

\section{CONCLUSION}

La présentation de ces dix-sept cas de réaffectation réalisées (ou en cours de réalisation) et les polémiques qu'elles ont pu susciter, nous amènent à penser qu'il en est des monuments comme des êtres humains : ils naissent, grandissent, tombent malades, vieillissent et finissent, tôt ou tard, par disparaître et mourir. La sauvegarde du patrimoine vise justement à conjurer, tout

26. Nous remercions vivement Laurent Borel pour sa coopération et le cliché de la citerne Ibn al-Nabîh qu'il a bien voulu mettre à notre disposition. 
au moins à retarder, cette ultime échéance. Cette métaphore facile, nous en conviendrons, a au moins le mérite d'être claire. Au cours de son existence, tout monument peut successivement connaître des avatars heureux ou malheureux. La mosquée Baybars au Caire en est un parfait exemple. Construite par le sultan al-Zâhir Baybars al-Bunduqdârî entre 1266 et 1269, elle traverse une période d'abandon, avant de connaître plusieurs réutilisations saugrenues: citadelle militaire lors de l'Expédition d'Égypte, caserne pour la communauté sénégalaise de Tekrour sous le règne de Muhammad 'Alî, entrepôt, savonnerie, abattoir lors de I'occupation anglaise, Q. G. pour les Forces de défenses civiles durant la guerre de 1956. Tout monument peut donc être assujetti à de nombreuses « réutilisations » ou "réaffectations ». Ces deux termes renvoient, ici, non pas au rétablissement d'un monument dans sa fonction première, mais à son remploi dans de nouvelles activités, quitte à lui inventer une vocation innovante, à lui forger carrément une nouvelle identité. La réaffectation marque donc une césure, un avant et un après. Certains monuments sont tellement uniques ou trop fragiles et délabrés pour pouvoir être réutilisés. Dans ce cas-là, il n'y a pas de mal à les restaurer et à les garder dans leur dernier état comme repères précieux et témoins remarquables d’une époque donnée. La restauration $\mathrm{n}^{\prime}$ aboutit pas nécessairement à une réutilisation; même si cette dernière implique quelques opérations de restauration. Autrement dit, la réhabilitation du palais de Muhammad 'Alî situé à Shubrâ n'est pas du tout une réaffectation, même si, moyennant 50 millions de livres égyptiennes, il ouvrira ses portes au public pour la première fois. Château il est, château il reste. Idem pour le splendide Sabîl-kuttâb cAbd al-Rahmân Katkhudâ (1157/1744) situé rue al-Mucizz à al-Nahhâsîn. Cette fontaine publique n'a pas été réutilisée depuis I'achèvement de sa restauration en 1995 par le CSA en coopération avec le Deutsches Archäologisches Institut Kairo (DAIK) et la compagnie IBM Egypt. En revanche, la conversion de Bayt al-Harrâwî, demeure bourgeoise

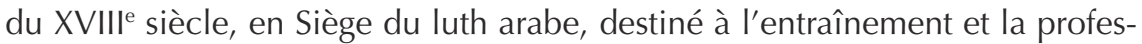
sionnalisation des luthistes amateurs, est un bel exemple de réaffectation. II en va de même de Bayt Ibrâhîm Agha Mustahfizân qui sera réutilisée comme un centre de santé pour l'enfance et la maternité, et abritera une petite clinique. En revanche, transformer un bâtiment historique en inspectorat pour le personnel pléthorique du CSA (trente mille fonctionnaires et archéologues) aurait pu être un mode valable de réaffectation si ce n'étaient les nombreuses dégradations généralement commises par ces utilisateurs et le peu d'entretien qu'ils accordent au monument qu'ils occupent.

Pour l'instant, les monuments pharaoniques échappent à toute réutilisation car ils sont relégués aux registres à la fois fascinant et inquiétant du sacré, de la mort et de I'au-delà. Aucune tentative n'a été expérimentée sur ce patrimoine cantonné dans le désert, aux confins des terres habitées. Contrairement aux monuments islamiques qui, eux, incarnent l'ici-bas, la vie, les échanges profanes et sont bien implantés au cœur du tissu urbain. Toutefois, malgré plusieurs expériences réalisées sur le terrain, la réutilisation du patrimoine isla- 
mique continue encore à diviser les responsables archéologiques égyptiens. Certains l'approuvent et y voient une chance pour ressusciter ces monuments, rehausser la conscience archéologique des citoyens, promouvoir la créativité artistique et culturelle, et dynamiser les zones historiques. D'autres, au contraire, rejettent cette idée, considérée comme source de détérioration des monuments. 